\title{
APHRA BEHNS GEDICHTE UND PROSAWERKE.
}

\section{Finleitung.}

Aphra Behn lebte in einer zeit, die zwar eine der interessantesten perioden der englischen kultur ist, die aber durch ihre schreckliche sittenverderbnis in einen üblen ruf gekommen ist. Wenn nun gar noch das leben und die werke einer frau, die ein echtes kind dieser zeit war, einer näheren untersuchung unterzogen werden, so mag dies sehr gewagt erscheinen. Aphra Behn gilt für viele nur als die „übelberüchtigte“. Hettner kennzeichnet sie als verderblich wirkende schriftstellerin und hat kein wort für Oroonoko. 1) Ward ist zwar fast noch mehr sittlich entrïstet über sie als Hettner; er weist aber wenigstens auf den Oroonoko als "good in many respects“ hin. ${ }^{2}$ ) Aber mit solchen urteilen kann man doch eine schriftstellerin von der bedeutung Aphra Behns nicht abthun. Schon die thatsache, dass sie diejenige gewesen ist, welche der erzählungslitteratur wieder zu grösserer bedeutung verhalf und gewissermassen das bindeglied zwischen dem 17. und 18. jahrhundert in bezug auf die erzählungslitteratur ist, lässt es als notwendig erscheinen, ihre bedeutung für das genannte litterarische gebiet einmal näher $\mathrm{zu}$ untersuchen. Dass Aphra Behn grössere bedeutung auf dem gebiete der erzählenden als auf demjenigen der dramatischen litteratur besitzt, darauf weist Wülker in seiner englischen litteraturgeschichte hin. ${ }^{3}$ ) Seitdem haben auch andere litterarhistoriker die bedeutung Aphra Behns als novellistin betont, so vor allem Rudolf Fürst, ${ }^{4}$ )

1) Hettner, a. a. 0. p. 120.

2) Ward, a. a. 0. p. 570 .

3) Wülker, a. a. 0. p. 358 . `) Fürst, a. a. 0. an verschiedenen stellen. 
L. Cross ') etc. - Das leben Aphra Behns bietet des interessanten soviel, dass eine kurzie biographie als zweckmässig erscheint.

\section{Aphra Behns leben und werke.}

So allgemein bekannt wie Aphra ${ }^{2}$ ) Behn zu ihrer zeit war, so wenig sind uns wirkliche thatsachen aus ihrem leben überliefert. Die biographie von einer ihrer freundinnen ${ }^{3}$ ) enthält nur wenig positives und lässt uns schon bald im stich. Andere biographische werke wiederholen in der hauptsache nur das, was in dieser biographie steht. Wir haben uns also in der hauptsache an letztere zu halten.

Ueber die vorfahren Aphra Behns wird nur gesagt, dass der vater Johnson hiess und in engen beziehungen zu Lord Willoughby gestanden habe. $\left.{ }^{4}\right)$ Es ist nicht ganz sicher festgestellt, wann und wo Aphra Behn geboren wurde. Die biographie sagt nur, dass „A.strea (der dichtername A. B.s) was a Gentlewoman by Birth, of a good Family in the City of Canterbury in Kent." $)$ ) Dagegen nimmt E. Gosse ${ }^{b}$ ) an, dass Aphra im jahre 1640 in dem orte Wye in Kent geboren sei. Er stützt sich dabei auf eine handschriftliche notiz der Lady Winchilsea in einem in seinem besitze befindlichen buche. Diese notiz gewinnt dadurch an wahrscheinlichkeit, dass, wie E. Gosse mitteilt, in dem taufregister von Wye die taufe eines mädchens Ayfara, der tochter des John und der Any Johnson, aufgezeichnet ist und zwar am 10. Juli 1640. Lady Winchilsea ${ }^{i}$ ) giebt ausserdem noch an, dass John Johnson ein barbier gewesen sei. Wie er aber als einfacher barbier in so nahe beziehungen zu Lord Willoughby gekommen sein und die hohe stellung eines gouverneurs von kolonien erreicht haben sollte, ist nicht recht klar. E. Gosse `) sagt nur, dass dieser bekannte und freund Willoughby's ein verwandter Aphras gewesen sei, den sie vater genannt habe. Liegt so schon auf

1) Cross, a. a. o. an verschiedenen stellen.

2) Der name kommt in den formen Afra, Aphra, Aphara, Ayfara vor.

3) The History of the Life and Memoirs of Mrs. Behn. Written by one of the fair Sex. Works V, $1 \mathrm{ff}$. (abigekürzt: L. and M.).

4) L. and M. p. $\left.2 . \quad{ }^{5}\right)$ L. and M. p. $\left.2 .{ }^{6}\right)$ E. Gosse im D. N. B.

7) E. Gosse a. a. $0 . \quad$ s) E. Gosse a. a. 0. 
der herkunft unserer schriftstellerin ein gewisses abenteuerliches dunkel, so ist ihr lebenslauf erst recht abenteuerlich. Ihr vater oder verwandter wurde von Lord Willoughby zum generallieutenant über sechsunddreissig inseln in der nähe von Surinam in Südamerika ernannt. ') Surinam ist die heutige holländische kolonie Guyana im nordosten von Südamerika; sie wird durchflossen von dem flusse Surinam, an dessen mündung die bekannte stadt Paramaribo liegt. Die besiedelung einiger der inseln, die unter dem namen Westindien bekannt sind, erfolgte durch Lord Francis Willoughby zu anfang der fünfziger jahre des 17. jahrhunderts. Willoughby kam am 2. April 1650 nach der insel Barbados. ${ }^{2}$ ) Die familie Johnson kann also nicht vor 1650 nach der neuen welt übergesiedelt sein, sodass Aphra noch in sehr jugendlichem alter stand. Daher mag die biographin in ihrer begeisterung für ihre freundin übertrieben haben, wenn sie erzählt, Aphra habe bei ihrer abreise viele betrübte freundinnen und anbeter mit „gebrochenen herzen“ zurückgelassen. ${ }^{3}$ ) Der neuernannte generallieutenant erreichte den ort seiner künftigen wirksamkeit nicht, sondern starb während der reise. Trotzdem setzte seine familie die reise fort und liess sich in Surinam nieder. ${ }^{4}$ ) Aphra giebt uns selbst eine beschreibung ihres wohnsitzes, die wegen ihrer anschaulichkeit hier wiedergegeben sei. ${ }^{5}$ )

As soon as I came into the Country, the best House in it was presented me, call'd St. John's Hill: It stood on a vast Rock of white Marble, at the Foot of which, the River ran a vast Depth down, and not to be descended on that Side; the little Waves still dashing and washing the Foot of this Rock, made the softest Murmurs and Turlings in the World; and the opposite Bank was adorn'd with such vast Quantities of different Flowers eternally blowing, and every Day and Hour new, fenc'd behind'em with lofty Trees of a thousand rare Forms and Colours, that the Prospect was the most ravishing that Fancy can create. On the Edge of this white Rock, towards the River, was a Walk, or Grove, of Orange and Lemon-Trees, about half the Length of the Mall ${ }^{8}$ ) here whose flowery and Fruit-bearing Branches met at the Top, and hinder'd the Sun, whose Rays are very fierce there, from entring a Beam into the Grove; and the cool Air that came from the River, made it not only
1) Oroonoko, works V, p. 152.
2) D. N.B. sub Francis Willoughby und Humphrey Walrond.
3) L. and M. p. 3. 3) Oroonoko, works V, p. 154.
s) Oroonoko, works V, p. 154-156.
6) In St. James's Park (Biogr. Brit.). 
fit to entertain People in, at all the hottest Hours of the Day, but refresh the sweet Blossoms, and made it always sweet and charming; and sure, the whole Globe of the World cannot shew so delightful a Place as this Grove was: Not all the Gardens of boasted Italy can produce a Shade to out-vie this, which Nature has join'd with Art to render so exceeding fine; and 'tis a Marvel to see how such vast Trees, as big as English Oaks, could take Footing on so solid a Rock, and in so little Earth as cover'd that Rock: But all Things by Nature there are rare, delightful, and wonderful.

Während des aufenthaltes in Surinam lernte Aphra den mann kennen, dessen leben und schicksale sie in ihrem umfangreichsten und besten prosawerk, in „The History of the Royal Slave“, erzählt. Sie berichtet uns in diesem werk, dass sie mit dem negerhäuptling Oroonoko, dem helden der erzählung, in regem verkehr gestanden und dass derselbe sie "his great Mistress" genannt habe. 1) Infolge der lebhaften schilderungen, die die schriftstellerin von dem neger und ihren beziehungen zu demselben giebt, entstand das gerücht, Aphra habe in mehr als freundschaftlichem verkehr mit Oroonoko gestanden. Die biographin bemüht sich, dieses gerücht zu widerlegen; sie meint, Aphra hätte ihr einmal nichts davon mitgeteilt, obgleich sie ihr sonst alle liebesaffären anvertraut hätte, dann sei Oroonoko von den reizen seiner farbigen gemahlin Imoinda viel zu sehr eingenommen gewesen. ${ }^{2}$ ) An und fïr sich ist es durchaus nichts ungewöhnliches, dass weisse frauen zu männern anderer rassen wirkliche liebe empfinden. Allein es ist unwahrscheinlich, dass das erwähnte gerïcht begründet war. Denn einmal war Aphra noch sehr jung und kaum schon einer tieferen sinnlichen neigung fähig, dann entsprach das urbild des negers wohl kaum den romanhaften schilderungen, die uns Aphra von ihm giebt.

Der aufenthalt Aphras in Surinam war nur kur\%. Sie kehrte schon mit einem der nächsten schiffe nach England zurück. ${ }^{3}$ ) Jedoch wird es damals ziemlich lange gedauert haben, ehe ein schiff aus der weit entfernten kolonie zurück kam. Ueber England brausten inzwischen die stürme der restauration. Karl II. stieg auf den thron Englands, der ein jahrzehnt hindurch verwaist war. Es war eine bewegte zeit,

') Oroonoko, works V, p. 149.

3) Oroonoko, works V, p. 152.

2) L. and M. p. 4. 
in der Aphra ihre heimat wiedersah. Sie kam selbst bald in nähere beziehungen zu dem hofe des „merry king“. Es ist nicht ganz klar, durch wen Aphra an den hof und in die unmittelbare nähe Karls II. kam. Cibber ${ }^{1}$ ) behauptet ohne nähere begründung, dass dies durch den holländischen kaufmann Behn geschehen sei. Aber sollte nicht schon ihre nahe bekanntschaft mit Lord Willoughby, der ein anhänger des königs war, genügt haben? Die beste empfehlung für die elegante, frivole hofgesesellschaft mögen wohl die schönheit und der lebhafte geist Aphras, eigenschaften, die die biographin mit rühmen hervorhebt, gewesen sein. Aphra unterhielt den könig und seine umgebung mit inren erlebnissen in Südamerika, vor allem mit der geschichte Oroonokos, die sie so gut erzählte, dass sie der könig zur veröffentlichung derselben aufforderte. ${ }^{2}$ ) Inzwischen hatte sich Aphra mit dem oben erwähnten Holländer Behn, der sich in London aufhielt, verheiratet. Diese ehe war jedoch nur von kurzer dauer. Nach den ansichten über die ehe, die sich in den verschiedenen werken, besonders in den lustspielen, der schriftstellerin finden, kann man kaum annehmen, dass Aphra ein musterhaftes zusammenleben mit ihrem gemahl geführt hat. Bei jeder gelegenheit wird über die fesseln der ehe gespottet; betrügerische und betrogene ehegatten spielen eine hauptrolle in den lustspielen. Ganz besonders aber sind das phlegma und die schwerfälligkeit der Holländer beliebte gegenstände des spottes für Aphra Behn, wie wir gelegentlich noch sehen werden. Die Holländer lernte Aphra noch näher kennen, aber erst nach ihrer ehe. Aphra muss sich an dem hofe Karls II. durch ihren beweglichen geist ausgezeichnet haben, denn der könig betraute sie mit einem wichtigen diplomatischen auftrage in dem kriege mit Holland, der 1667 durch den frieden von Breda sein ende erreichte. Die junge dame wurde von Karl II. nach Antwerpen geschickt, um die kriegspläne der Holländer zu erforschen. ${ }^{3}$ ) Dies gelang ihr auch sehr gut, allerdings in einer weise, die charakteristisch für jene sittenlose zeit ist und die beweist, dass Aphra durch den einfluss des englischen hofes zwar eine schlaue diplomatin, aber auch

2) Cibber, a. a. o. p. 18.

2) L. and M. p. 5 .

8) L. and M. p. 5 . 
eine weltgewandte, intrigante abenteurerin geworden war. Ein junger holländischer kaufmann, Van der Albert, hatte sich bei seinem aufenthalt in London vor dem kriege in die schöne gattin seines landsmannes Behn verliebt. 1) Als er erfuhr, dass Aphra nach Antwerpen gekommen war, eilte er sogleich in diese stadt. Die diplomatin benutzte nun die liebe des jungen mannes, der eine wichtige stellung in seinem vaterlande einnahm, um dem bethörten die wichtigsten geheimnisse zu entlocken. In seiner verblendung entdeckte er der geliebten frau den kühnen plan der Holländer, die englischen schiffe in der Themse zu verbrennen. Sofort benachrichtigte Aphra die londoner regierung von ihrer wichtigen entdeckung. Allein die regierung, an deren spitze der bekannte minister Clarendon stand, nahm keine notiz von der mitteilung. Man lachte über den eifer der diplomatin, die an so abenteuerliche pläne glauben konnte. Finem freunde, der ihr dies mitgeteilt hatte, schrieb sie folgenden brief, aus welchem hervorgeht, dass sie eine klare einsicht in die kleinliche, egoistische politik der leitenden staatsmänner besass. ${ }^{2}$ )

My dear Friend,

Your Remarks upon my politick Capacity, tho' they are sharp, touch me not, but recoil on those that have not made Use of the Adrantages they might have drawn from thence, and are doubly to blame: First, In sending a Person, in whose Ability, Sense, and Veracity, they could not confide; and next, Not to understand when a Person indifferent tells 'em a probable Story, and which if it come to pass, would sufficiently punish their Incredulity; and which, if follow'd, would have put 'em on their Guard against a vigilant and industrious Foe, who watch'd every Opportunity of returning the several Repulses, and Damages, they had met with of late from them. But I have often observ'd your busy young Statesmen, so very opinionated of their own Designs, that they are so far from encouraging those of another, if good, that they cannot forgive their Proposal, and sacrifice a publick Good to their particular Pride.

Die strafe folgte denn auch bald diesem leichtsinn der englischen regierung. Im Juni 1667 segelte eine holländische flotte unter ihrem kühnen führer de Ruyter in die Themse und setzte die auf dem strome befindlichen englischen schiffe in brand. ${ }^{3}$ ) So war es der unermüdlichen frau nicht gelungen,

1) L. and M. p. 7. $\quad$ 2) Der brief ist abgedruckt in L. and M. p. 11 .

3) 0. Jäger, Weltgesch. III, p. 369. 
die gefahr von ihrem vaterlande abzuwenden. Van der Albert scheint für seinen dienst nicht nach seinem wunsche belohnt worden zu sein; darauf deuten die folgenden worte in der biographie: „Astrea could not doubt but Van der Albert had sufficient Grounds for what he had told her, and scarcely allow'd that little Time that Albert staid, to the Civilities due for a Service of that mighty Consequence." I) Aphra scheint die liebe des Holländers nur geduldet zu haben, um diesen auszunutzen; im übrigen behandelte sie ihn als einen gegenstand ihres spottes, ebenso wie einen seiner verwandten, namens Van Bruin. Ihr verkehr mit diesen beiden männern ist ein charakteristischer beweis für ihr abenteuerreiches leben in Antwerpen. Aphra hat Van der Albert eines abends in ihre wohnung geladen. Aber sie bleibt nicht selbst zu hause, sondern schickt eine frühere geliebte Alberts in ibre wohnung. Albert bemerkt den betrug erst am nächsten morgen. Um sich dafür zu rächen, besticht Albert die gesellschafterin Aphras und legt sich in deren kleidern im schlafzimmer seiner angebeteten, die den abend bei "play and mirth" in einer bekannten kaufmannsfamilie zubringt, nieder. Aphra beschliesst bei ihrer heimkehr, ihre alte gesellschafterin dadurch $\mathrm{zu}$ erschrecken, dass sie den jungen mann, der sie nebst seinen beiden schwestern nach hause begleitet, allein in ihre wohnung schickt. Zum grössten erstaunen findet man aber nicht die alte dame, sondern Van der Albert im bett, der zur strafe für seine that Aphra die ehe versprechen muss! Aber schon bald darauf starb Albert in Amsterdam am fieber während der vorbereitungen zur reise nach England. ${ }^{2}$ )

Das erzählte abenteuer war nicht das einzige, das Aphra in Antwerpen erlebte. Man musste auch schon in London an ihre pikanten erlebnisse gewöhnt sein, denn einer ihrer freunde schreibt ihr, sie solle sich von der politik abkehren und lieber „divert her Friends with some pleasant Adventures of Antwerp, either as to her Lovers or those of any other Lady of her Acquaintance: that in this she would be more successful than in her Pretences of State, since here she would not fail of pleasing those she wrote to ". ${ }^{3}$ ) Diesem wunsche ihrer freunde kam sie denn auch nach. Durch ihren misserfolg
1) L. and M. p. 9.
2) L. and M. p. 38 .
3) L. and M. p. 10. 
entmutigt, gab sie ihre politische thätigkeit auf und beschäftigte sich mit litterarischen dingen; so sammelte sie in Holland den stoff $z u$ einer ihrer gewandtesten erzählungen, zu „Tarquin und Miranda", und berichtete ihren freunden in der heimat über ihre erlebnisse. Von diesen will ich noch eins hier anführen, da es für den charakter unserer schriftstellerin bezeichnend und für ihre schriftstellerische thätigkeit wichtig ist. Aphra schildert in ihren briefen aus Antwerpen die Niederländer als geizige, gewinnsüchtige, hartherzige menschen, deren sinn nur auf geld und alkohol gerichtet sei. Um so mehr glaubt sie sich rühmen zu dürfen, dass sie die herzen zweier dieser geldjäger bezwungen habe, nämlich die Van der Alberts und Van Bruins. - Letzterer muss eine art bankier für Aphra gewesen sein, denn er versah sie im auftrage Alberts mit dem nötigen geld. - Schon nach den ersten begegnungen verliebt sich Van Bruin, ein schon bejahrter mann, in die schöne abenteurerin. Die leidenschaft reisst ihn aus seinem stumpfen phlegma. Er versucht sogar witzig zu sein und schreibt an die geliebte frau einen liebesbrief in affektierter, schwülstiger sprache, worin er einen ausführlichen vergleich zwischen Aphra und einem schiffe macht. Aphra schreibt in demselben lächerlichen stil eine scheinbare zusage, worauf Bruin seine werbungen in ebenso manierierter sprache mündlich in ihrer wohnung vorbringt, zur grossen belustigung Aphras. Schliesslich wird ihr die sache zu langweilig; sie benachrichtigt Van der Albert von dem verliebten treiben seines verwandten. Wie der alte narr sieht, dass er nur zum spotte dient, zieht er sich von Antwerpen zurück und lässt sich dort nicht wieder sehen.

Die gestalt des alten verliebten geizhalses, der zum schluss der dumme ist, kehrt oft in den werken Aphra Behns wieder; es haben ihr sicher dabei ihre erlebnisse in den Niederlanden vor augen geschwebt. In den briefen macht sich auch schon das talent für lebhaftes erzählen bemerkbar.

Die erzählten erlebnisse Aphras hatten sich gegen ende des jahres 1666 zugetragen. 1) Kurz darauf kehrte Aphra über Ostende und Dünkirchen nach England zurück. Auf der fahrt über den kanal wurde das schiff von einem sturm über-

1) L. and M. p. 8. 
rascht, an die küste geschleudert und zertrümmert. Die schiffbrüchigen, unter ihnen Aphra Behn, wurden von küstenbewohnern an das land gerettet.

"Our Astrea arrived safe, tho' tir'd, to London, from a Voyage that gain'd her more Reputation than Profit. The rest of her Life was entirely dedicated to Pleasure and Poetry; the Success in which gain'd her the Acquaintance and Friendship of the most sensible Men of the Age, and the Love of not a few of different Characters." ${ }^{1}$ )

Von hier an verlässt uns die hauptquelle für Aphra Behns leben, die biographie. Es werden nur noch acht briefe mitgeteilt, welche die schriftstellerin an einen freund, den sie Lycidas nennt, geschrieben hat. ${ }^{2}$ ) Nach dem ton der briefe $\mathrm{zu}$ urteilen, scheint mit dem namen Lycidas ein mann aus höheren kreisen gemeint zu sein, der ihr nicht die gegenliebe schenkte, die sie erwartete. Die briefe lassen in Aphra Behn einen leidenschaftlichen, unruhigen charakter erraten. Sie nennt sich selbst „a Woman violent in all her Passions", dann wieder eine "stolze und trotzige" natur. ${ }^{3}$ ) Wie sie zwischen stolz und liebe kämpft, möge die folgende stelle aus Letter VII ${ }^{4}$ ) zeigen :

My Soul is ready to burst with Pride and Indignation; and at the same 'Time, Love, with all his Softness, assails me and will make me write: so that between one and the other, I can express neither as I ought. What shall I do to make you know I do not use to condescend to so much Submission, nor to tell my Heart so freely? Tho' you think it Use, methinks I find my Heart swell with Disdain at this Minute, for my being ready to make Asseveration of the contrary, and to assure you I do not, nor never did love, or talk at the Rate I do to you, since I was born: I say, I would swear this, but something rolls up my Bosom, and checks my very Thought as it rises. You ought, Oh Faithless, and infinitely Adorable Lycidas! to know and guess my Tenderness; you ought to see it grow, and daily increase upon your Hands. If it be troublesome, 'tis because I fancy you lessen, whilst I increase, in Passion; or rather, that by your ill Judgment of mine, sour never had any in your Soul for me. Oh unlucky, oh vexatious Thought! Either let me never see that charming Face, or ease my Soul of so tormenting an Agony, as the cruel Thought of not being belov'd. Why, my lovely Dear, should I flatter you? Or, why make more Words of my Tenderness,

1) L. and M. p. 40 .

2) Love-Letters to a Gentleman. By Mrs. A. Behn. Printed from the Original Letters. Works $\mathrm{V}, 54 \mathrm{ff}$.

8) L. and M. p. 56 个) Works V, $66 \mathrm{f}$. 
than another Woman, that loves as well, would do, as once rou said? No, you ought rather to believe that I say more, because I have more than any Woman can be capable of: My Soul is form'd of no other Material than Love.

Die Love Letters können nicht vor beginn der siebziger jahre geschrieben sein, denn in dem einen ${ }^{1}$ ) spricht sie davon, dass sie einen akt aus ihrem neuen stück vorgelesen habe. Ihr erstes stück wurde aber erst 1671 aufgeführt. ${ }^{2}$ )

Seit ende des jahres 1666 weilte also Aphra Behn in London. Es ist nicht wahrscheinlich, dass sie für ihre der politik geleisteten dienste belohnt worden ist, im gegenteil lachte man nur über sie, wie wir gesehen haben. So musste sie versuchen, auf eine andere art ihren lebensunterhalt zu erwerben. Diese reale forderung war jedenfalls der hauptanlass zu der schriftstellerischen thätigkeit Aphra Behns. Langbaine ${ }^{3}$ ) berichtet, dass sie selbst der welt bekannt habe, sie hätte, wenigstens die erste zeit, für brot schreiben müssen. Dass sie gerade schriftstellerin wurde, ist bei ihrem lebhaften temperament sehr begreiflich. Die oben genannte materielle forderung erklärt auch die ungemeine fruchtbarkeit, die Aphra Behn im dichten entwickelte; sie verfasste ausser anderen werken allein siebzehn dramen. Die litterarische produktion war besonders auf dem dramatischen gebiete in der restaurationszeit ausserordentlich rege. Dichten gehörte in der feinen gesellschaft zum guten ton. Es gab unter den aristokraten viele dichter, die ohne rücksicht auf pekuniären erfolg die bühne mit dramen versahen und die nur dichteten, um sich einen berühmten namen zu erwerben; z. b. leute wie Sir G. Etherege, Sedley, Rochester etc. Dadurch thaten sie ihren ärmeren kollegen, die von dem ertrag ihrer dichterischen erzeugnisse leben mussten, in pekuniärer hinsicht grossen abbruch. Ausserdem brachten die aufführungen den dichtern selten grossen gewinn; denn der autor hatte erst an dem gewinn der dritten vorstellung seines dramas anteil. ${ }^{4}$ ) Das publikum scheint auch nicht gern viel für das theater ausgegeben zu haben, denn es begegnen uns in den dramen Aphra Behns öfter klagen über die geringe teilnahme der

1) Letter VI, works V, p. 63.

t) Beljame, a. a. 0.

2) cf. p. $98 \mathrm{f}$.

s) Langbaine, a. a. 0 . 
theaterbesucher. ') Die unterstützung, die man von dem lebenslustigen hof erwarten könnte, war, wie wir nach verschiedenen zeugnissen wissen, nicht gerade ansehnlich. Nicht einmal die dichter, die für das königtum eintraten, konnten sich einer besonderen unterstützung von seiten des hofes rühmen, wie das beispiel Butlers beweist, der, obgleich er der "lieblingsdichter Karls II. war, halb verhungert in London starb“. ${ }^{2}$ ) Aphra Behn war also wohl gezwungen, viel zu schreiben, um etwas zu verdienen. Dass sie bei dieser massenarbeit keine originalen dramen dichtete, sondern hauptsächlich nur bearbeitungen von werken der heimischen und ausländischen litteraturen, ist nicht zu verwundern. Dieses verfahren hatten schon vor ihr manche dichter eingeschlagen, so Davenant, Wilson und auch Dryden. ${ }^{3}$ ) Man hielt es also durchaus nicht für nötig, originale werke zu dichten. Erstens brauchte man $\mathrm{zu}$ viel stücke für die vorstellungen, und dann lebte in dieser zeit kein genialer dichter, der ähnlich wie Shakespeare selbständige werke hätte schaffen können. Selbst Dryden war nur ein dichter zweiten ranges, so sehr er auch von seinen landsleuten gepriesen wird.

Der zeitpunkt der ersten dichterischen thätigkeit Aphra Behns lässt sich nur annähernd feststellen. Nach dem berichte ihrer biographin dichtete sie schon als kind "the prettiest, soft, engaging Verses in the World "..4) Von diesen versen wird wohl wenig oder gar nichts übrig geblieben sein. Die zeit und gedanken Aphras wurden ja schon in ihrer jugend für ganz andere dinge in anspruch genommen, zunächst für ihre grosse reise über das meer und ihren aufenthalt in Surinam. Nach ihrer rückkehr nach London muss sich unsere schriftstellerin durch ihr erzählertalent ausgezeichnet haben, wie der erfolg, den sie mit dem bericht ihrer abenteuer in Surinam bei dem könig erntete, beweist. Ob sie freilich dessen aufforderung, die geschichte Oroonokos $\mathrm{zu}$ veröffentlichen, sogleich befolgt hat, ist, wie sich später zeigen wird, nicht wahrscheinlich. Wir können aber annehmen, dass sie nach der sitte der feinen gesellschaft, in der sie in London verkehrte,

1) Epiloge zu The Rover, part II, Dutch Lover, The Faign'd Curtezans.

2) Wülker, a. a. o. p. $346 . \quad$ s) Wülker, a. a. 0. p. 351 ff.

c) L. and M. p. 3. 
kleinere gedichte, wie sie sie später veröffentlichte, verfasste. Erst nach ihrem aufenthalt in Antwerpen wird sie dann ernstlich an die schriftstellerei herangegangen sein. Hatte sie aber die absicht, den beruf einer schriftstellerin zu ergreifen, so musste sie zunächst auf dramatischem gebiete thätig sein; denn das hauptinteresse der zeit wandte sich der bühne $\mathrm{zu}$, die sich nach den für sie so schweren zeiten der puritanerherrschaft wieder kräftig entwickelte. Allerdings war der neue geist, der auf der bühne zu herrschen begann, gänzlich verschieden von dem der shakespeareschen zeit. Das theater wurde zum schauplatz frivoler, sittenloser lustspiele und pomphafter, rhetorischer dramen, der von Dryden besonders gepflegten, aus Frankreich gekommenen "heroic plays“. Beiden arten der dramatischen dichtung wandte sich Aphra Behn zu, mit besonderer vorliebe aber dem lustspiel. Und was dieses anbelangt, so stand Aphra Behn ihren männlichen kollegen in nichts nach. Ihre lustspiele sind von einer erschreckenden frivolität und sittenlosigkeit erfüllt. Trotz der gewandten sprache und der lebhaften, pointierten dialoge wäre eine aufführung der lustspiele Aphra Behns jetzt ganz undenkbar; dazu gehörte eine in der sitte so verderbte zeit wie das restaurationszeitalter. Es wäre nun sicher verfehlt, eine ehrenrettung Aphra Behns für ihre lustspiele zu unternehmen und die in letzteren enthaltenen unflätigkeiten entschuldigen zu wollen. Aber andererseits ist man zu weit gegangen, wenn man wie Ward 1) die ganze dramatische produktion der schriftstellerin mit sittlicher entrüstung abthut. Denn in Aphra Behn lag ganz unstreitig ein tüchtiges talent. Ihre lustspiele sind nicht unsittlicher als die ihrer zeitgenossen Etherege, Wycherly etc. Allerdings wäre der einwurf, dass Aphra Behn als angehörige des zarten geschlechts die pflicht gehabt hätte, die frauenwiirde zu bewalren, nicht unberechtigt. Aber auf der ander'n seite bewährt sie einen männlichen mut - wie wir bei der besprechung von Oroonoko sehen werden -, dem wir unsere sympathie nicht versagen können. Dazu kommt, dass sie den forderungen der zeit nachgeben musste, wemn sie erfolg haben wollte, und es hat doch viel grössere dichter gegeben, die sich dem geschmack des publikums, auch wenn

1) Ward, a. a. o. p. 570 .

Anglia. N. F. XIII. 
sie ihn nicht billigten, gefügt haben. Wir werden weiter unten noch näher nachzuweisen versuchen, wie Aphra Behn nicht von vorn herein der verderbten zeitströmung folgte; doch es sei schon hier eine stelle aus ihren werken citiert, die beweisst, dass Aphra Behn nur widerwillig sich nach dem publikum richtete: ${ }^{1}$ )

The scanted Tribute is so slowly paid, Our Poets must find out another Trade;

They 've try'd all Ways th' insatiate Clan to please,

Have parted with their old Prerogatives,

Their Birth-right Satiring, and their just pretence

Of judging even their own Wit and Sense;

And write against their Consciences, to show

How dull they can be, to comply with you.

Im lustspiel spiegelt sich am besten das tägliche leben wieder, und dass die lustspiele der restaurationszeit in ihren darstellungen der sittenlosigkeit nicht übertreiben, dafür zeugen belege ${ }^{2}$ ) aus dem leben hoher aristokraten. Denn diese waren es, die in einem pfuhl der ärgsten sittenverderbnis versunken und die das massgebende publikum im theater waren. Von der aristokratie aus verpflanzte sich die sittenverderbnis in weitere kreise, die nach der strengen puritanerherrschaft mit ihren asketischen tendenzen für ein ausschweifendes leben empfänglich geworden waren. Einem solchen publikum stand Aphra Behn gegenüber. Schwer wird es ihr allerdings nicht geworden sein, diesen leuten die rechte ware vorzusetzen; denn sie kannte das leben am hofe und hatte selbst schon nicht unbedenkliche abenteuer hinter sich. Nichtsdestoweniger werden wir in ihren erstlingswerken ernste, sittliche tendenzen finden. ${ }^{3}$ )

Als ersten dramatischen versuch, für den sich kein verleger und theaterdirektor fand, bezeichnet E. Gosse ${ }^{4}$ ) das drama "The Young King, or, The Mistake“.5) Es ist ein

1) Epilog zu The Rover, part II, works I, p. 185.

2) Beljame, a. a. o.; Pepys, Diary etc., dazu Aronstein, a. a. 0.

3) Da die behandlung der dramatischen werke Aphra Behns nicht in den bereich meiner aufgabe fällt, so kann ich nur insoweit auf dieselben eingehen, als sie für die entwickelung des charakters und für den lebenslauf der dichterin in betracht kommen.

b) E. Gosse, a. a. $0 . \quad$ s) Works II, p. $88 \mathrm{ff}$. 
romantisches drama im stile Drydens. Auch das nächste stück ist ein romantisches, es heissst "The Forc'd Marriage, or, The Jealous Bridegroom" 1 ) und wurde aufgeführt und gedruckt im jahre 1671. Noch in demselben jahre brachte Aphra Behn ihr erstes lustspiel auf dies bühne, nämlich "The Amorous Prince“. 2) Trotz der bezeic.hnung ,a Comedy" ist die haupthandlung eine ernste; nur eeinige episoden sind lustspielartig. Erst das folgende stiick, "T'We Dutch Lover", ${ }^{3}$ ) 1673, ist ein echtes lustspiel. Wie der tiitel schon besagt, ist der held ein Holländer. Es ist dies deshralb von besonderem interesse, weil England im jahre 1672 an Holland den krieg erklärt hatte. Aphra Behn hat gewiss niccht ohne absicht gerade den vorliegenden stoff gewählt. Inı dem titelhelden wird ein reicher, aber schwerfälliger und unigebildeter, dem trunk ergebener Holländer dargestellt. Das lustspiel sollte wohl dazu dienen, die Holländer lächerlich zu machen, ähnlich wie sie Dryden in seinem drama „Amboyna., or, the Cruelties of the Dutch to the English Merchants" iin den augen der Londoner herabsetzen wollte. $\left.{ }^{4}\right)$

Während der nächsten! drei oder vier jahre hören wir nichts von der aufführung boehnscher dramen. Aphra muss in dieser zeit trotzdem sehr thiätig gewesen sein, denn 1677 gab sie mehrere dramen zugleicch heraus. Zuerst ist zu nennen "Abdelazar, or, The Moorr's Revenge". ${ }^{5}$ ) Es ist dies die einzige tragödie Aphra Behnns; sie wurde im jahre 1676 aufgeführt. ${ }^{6}$ )

Mit Abdelazar müssen 'wir einen abschnitt in der dichterischen thätigkeit Aphra Belnns machen. Die dramen der folgenden periode sind gekemnzeichnet durch die eigenschaften, durch welche sich die schriftstellerin ein zwar bleibendes, aber zweifelhaftes andenkern erworben hat, nämlich durch frivolität und sittenlosigkeit.. Allein in den bisher genannten werken tritt Aphra Behn mutig den lastern ihrer zeit entgegen und schont dabei aucch nicht den adel. Zum beweise dafür müssen wir kurz auf 'das bemerkenswerteste drama der ersten periode eingehen, auf "The Amorous Prince". Der held, ein ritterlicher aber umbeständiger prinz, hat sich in ein

1) Works III, p. $253 \mathrm{ff.}{ }^{2}$ ) Works IV, p. $257 \mathrm{ff.} \quad$ s) Works I, p. $186 \mathrm{ff}$.

๑) Wülker, a. a. 0. p. $354 . \quad$ (s) Works $\amalg$, p. $3 \mathrm{ff}$. (3) E. Gosse, a. a. 0. 
in einsamkeit und unschuld lebendes mädchen von hohem stande, das als arme hirtin verkleidet ist, verliebt, und findet die zärtlichste gegenliebe. Er verspricht der geliebten, sie trotz ihres scheinbar niederen standes zu seiner gemahlin zu erheben. Seiner unbeständigkeit aber und den böswilligen ratschlägen eines feilen höflings folgend, verlässt er die geliebte und verfolgt die braut seines freundes, der zugleich der bruder des vom prinzen verlassenen mädchens ist, mit liebesanträgen. In letzterem kämpfen die gefühle des beleidigten bruders and liebhabers gegen die pflichten als freund und unterthan des prinzen. Es kommt aber nicht zum ausbruch des tragischen konflikts, da der prinz sich die klagen und mahnungen des beleidigten freundes zu herzen nimmt und auf den weg der pflicht zurückkehrt, indem er sein eheversprechen einlöst, vor allem nachdem er erfahren hat, dass die vermeintlich arme hirtin von hohem stande ist. Diese gewaltsame lösung mit dem deus ex machina ist ein beweis für die grosse kluft zwischen den verschiedenen ständen der damaligen zeit; die arme hirtin wäre sicher dem elend verfallen, wenn sie sich nicht noch als aristokratin entpuppt hätte. Der ausgang des dramas entspricht also ganz den anschauungen der zeit. Trotzdem ist dieses stïck ein beweis für den mut Aphra Behns; denn die verfasserin nimmt öfters gelegenheit, für den stand der unterdrückten, besonders für hilflose frauen einzutreten und den kavalieren vor augen zu führen, welches elend sie mit ihrem leichtsinn anrichten können. Als vertreter der aristokratie wählt Aphra Behn einen prinzen. Es wird im stïcke zwar immer gesagt, dass einem prinzen mehr erlaubt sei als einem andern sterblichen; aber es wird ihm auch klar bedeutet, dass er seine macht nicht dazu missbrauchen darf, schutzlose frauen in kummer und elend $\mathrm{zu}$ stürzen und seine besten freunde zu betrügen. So ruft ihm der bruder des verlassenen mädchens zürnend $\left.\mathrm{zu}:{ }^{1}\right)$

First, Sir, you have debauch 'd my lovely Sister, The only one I had;

The Hope and Care of all our noble Family:

Thou Prince didst ravish all her Virtue from her, And left her nothing but a desperate sense of Shame.

1) Akt V, sc. 3, works IV, p. 331 f. 
Next, (Oh how unlike a brave and generous Man!)

Without a Cause, you cast me from your Bosom;

Withdrew the Honour of your promis'd Friendship,

And made me Partner in my Sister's Fate;

Next, Sir, you ravish'd Laura (seine braut) from me,

And under a pretence of sacred Friendship,

You prov'd your self the worst of Enemies.

Aphra Behn hat sogar die kühnheit, einen diener, also den vertreter eines untergeordneten standes, den leichtfertigen lebenswandel des prinzen ironisch kritisieren zu lassen. Der bediente des prinzen hat von seinem herrn einen auftrag in einer zweideutigen liebesaffäre erhalten; bevor er denselben aber ausführt, ruft er: ') "Well, even Frederick (der prinz), I see, is but a Man, but his Youth and Quality will excuse him; and 'twill be call'd Gallantry in him, when in one of us, 'tis Ill-nature and Inconstancy."

Den übergang zu der zweiten periode bildet das lustspiel "The Dutch Lover". Es finden sich hier schon recht pikante scenen. Die männer sind ausschweifend und frivol, aber sie werden bekehrt durch liebende, ehrenhafte und mutige frauen. Es ist in der that noch kein Baudy A-la-Mode, wie die verfasserin im epiloge ${ }^{2}$ ) sagt. Aber mit dem folgenden lustspiel, "The Rover, or, The Banish'd Cavaliers", ${ }^{3}$ ) 1677, beginnt die reihe der unsittlichen komödien. Das genannte stïck ist voll von schamlosen scenen und charakteren; auch die frauengestalten haben jeden anspruch auf achtung verloren. Es seien hier nur einige aussprüche des helden angeführt, die für das niveau dieses und der folgenden lustspiele charakteristisch sind. „A virtuous Mistress! Death, what a thing thou hast found out for me! why what the Devil should I do with a virtuous Woman? - a sort of ill-natur'd Creatures, that take a Pride to torment a Lover. Virtue is but an infirmity in Women, a Disease that renders even the handsom ungrateful; whilst the ill-favour'd for want of Sollicitations and Address, only fancy themselves so." ${ }^{4}$ ) In derselben scene äussert sich dieser "held" über framenehre folgendermassen: "Honour! I tell you, I hate it in your Sex; and those that fancy themselves possest of that Foppery, are the most impertinently

1) Akt II, sc. 1, works IV, p. $280 . \quad$ 2) Works I, p. 283.

`) Works I, p. $1 \mathrm{ff}$ 4) Akt IV, sc. I, works I, p. 60. 
troublesom of all Womankind." Ganz und gar verhasst aber ist ihm die ehe: „Priest and Hymen! prithee add Hangman to 'em to make up the Consort." 1) - Aphra Behn war sich wohl bewusst, was für ein unweibliches produkt sie geschaffen hatte, denn sie liess das lustspiel anonym erscheinen. ${ }^{2}$ ) Allein sie hatte damit den geschmack ihrer zeit getroffen; die komödie errang grossen beifall; der herzog von York selbst hatte besonderes gefallen daran. ${ }^{3}$ ) Durch diesen erfolg ermutigt, lies die verfasserin vier jahre später einen zweiten teil $\mathrm{zu}$ dem lustspiel erscheinen, wobei sie sich als autor zu erkennen gab. Sie widmete diesen zweiten teil dem herzog von York. ${ }^{4}$ )

Zwischen dem ersten und zweiten teil des Rover liegen noch vier andere lustspiele, „The Debauchee“, ${ }^{5}$ ) „The Town Fop, or, Sir Timothy Tawdrey"6) und „Sir Patient Fancy“.7) Das erste ist nicht mit sicherheit Aphra Behn zuzuschreiben; es findet sich weder bei Langbaine noch in anderen bibliographischen werken verzeichnet; nur E. Gosse ${ }^{8}$ ) nennt es ein anonymes werk der dichterin. Alle drei genannten lustspiele erschienen 1677. Bis zum jahre 1681 veröffentlichte Aphra Behn nur noch eine komödie ausser dem zweiten teil des Rover, nämlich „The Feign'd Curtezans, or, A Night's Intrigue“, $\left.{ }^{9}\right)$ 1679. Gerade um diese zeit wirkte die gestaltung der politischen verhältnisse ungünstig auf das theater. Gegen ende der siebziger jahre des 17. jahrhunderts hatten sich die gegensätze zwischen dem hof und dem volke scharf zugespitzt. Es waren streitigkeiten zwischen parlament und könig ausgebrochen über die thronfolge Jakobs, des katholischen herzogs von York. Letzterer hatte sich entschliessen müssen, London mehrere male zu verlassen, um die aufgeregte feindliche partei zu beschwichtigen. Im ganzen lande hatten sich zwei grosse parteien gebildet, die whigs und tories, die gegner und anhänger des herzogs. $\mathrm{Zu}$ letzteren gehörte vor allem die aristokratie, die sich um den könig scharte. Die schriftsteller waren gezwungen, sich für eine der beiden parteien zu entscheiden und ihre kunst in den dienst der politik zu stellen.

1) Akt V, sc. 1, works I, p. 87. 2) E. Gosse, a. a. 0. $\left.{ }^{3}\right)$ E. Gosse, a. a. 0.

5) Langbaine, a. a. o. 5) Fehlt in den works. क) Works III, p. $3 \mathrm{ff}$.

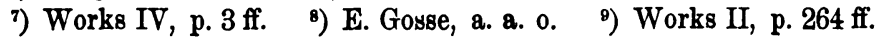


Aphra Behn war schon früh:zeitig in beziehungen zu dem hofe getreten, und sie blieb demselben auch zeitlebens treu. Sie trat für die tories mit ihrem schriftstellerischen talent kräftig ein. Ein zeitgenosse rühmtt sie gerade wegen ihres treuen festhaltens an der königlichten sache ${ }^{1}$ )

Long may she (A. B..) scourge this mad rebellious Age,

And stem the torrentt of Fanatick rage,

That once had almosst overwhelm'd the Stage.

0 'er all the Land the dire contagion spread,

And e'en Apollo's Soms apostate fled:

But while that spuriious race imploy'd their parts

In studying stratagemms and subtile arts,

To alienate their Priince's Subjects hearts,

Her Loyal Muse still tun'd her loudest strings,

To sing the praises of the best of kings.

Schon im Rover dientt die schriftstellerin der „Royal Cause" insofern, als sie darin englische kavaliere darstellt, die wegen ihrer parteinahme für den könig ihr vaterland verlassen und, ihres eigentums.lberaubt, in der fremde herumirren müssen. Die geschilderten verhältnisse beziehen sich zwar auf die zeiten der revolution; aber es drohten wieder ähnliche verhältnisse einzutreten wiie 1649 . Ueberall glaubte man verschwörungen gegen das königshaus auf der spur zu sein. In dieser allgemeinen politischen aufregung fand man keine zeit für das theater. Apthra Behn lässt einen schauspieler folgendermassen klagen : ${ }^{2}$ )

The Devil take this cursed plotting Age,

'T has ruin'd all ourr Plots upon the Stage;

Suspicions, New Eleections, Jealousies,

Fresh Informations, New Discoveries,

Do so employ the busy fearful Town,

Our honest Calling there is useless grown:

Each Fool turns Pollitician now, and wears .

A formal Face, and talks of State-affairs;

Makes Acts, Decrees;, and a new Model draws

For Regulation both of Church and Laws;

Tires out his empty Noddle to invent

What Rule and Metthod's best in Government:

But Wit, as if ' $t$ wrere Jesuitical,

Is an Abomination tto ye all.

1) To the Lovely Witty Aistræa, on her Excellent Poems; in den Poems von 1684; der verfasser dies gedichts nennt sich nicht.

2) Prolog zu The Feign'd Curtezans, works II, p. 264. 
Die dinge nahmen aber schliesslich eine günstige wendung für die tories. Die whigs wurden unterdrückt und verfolgt. Diese gestaltung der dinge spiegelt sich deutlich in der gleichzeitigen litteratur wieder, besonders in der dramatischen, für die man wieder mehr interesse zu zeigen begann, wenn auch nie wieder in dem hohen masse wie vorher. Die toryistisch gesinnten dichter fanden jetzt günstige gelegenheit, dem hof ihre treue anhänglichkeit zu beweisen. Auch Aphra Behn schrieb drei lustspiele im dienste der "Royal Cause", nämlich "The City Heiress, or, Sir Timothy Treat-all“, 1) „The Roundheads, or, the Good Old Cause" ${ }^{2}$ ) und "The False Count, or, A new way to play an Old Game". ${ }^{3}$ ) Alle drei stücke erschienen 1682; das letzte hatte sie in fünf tagen verfasst. ') In diesen lustspielen schleudert Aphra Behn ihren ganzen spott und hohn auf die whigs. Die männel sind feig, beschränkt, heuchlerisch und lüstern, ihre frauen ebenso heuchlerisch und betrügerisch; sie betrügen mit den kavalieren, d. h. den anhängern des königtums, ihre männer. Die kavaliere dagegen sind ebenso tapfer wie witzig, galant und ritterlich, der sache des königs treu ergeben. Aphra Behn lässt sich dabei die gelegenheit nicht entgehen, das lob ihres königs $\mathrm{zu}$ singen, ohne sonderlich auf die situation rücksicht zu nehmen. Bezeichnend dafür ist eine stelle in der zweiten scene des vierten aktes von The Roundheads. Loveless, ein „kavalier", befindet sich beim zärtlichen rendez-vous mit Lady Lambert 5) in deren zimmer. Da sieht er auf einem tische die königlichen insignien liegen, die ihn zu einer begeisterten rede hinreissen : ${ }^{6}$ )

Hah-a Crown and Scepter!

Have I been all this while

So near the sacred Relicks of my King,

And found no awful Motion in my Blood,

Nothing that mor'd sacred Devotion in me?

- Hail sacred Emblem of great Majesty,

Thou that has circled more Divinity

Than the great Zodiack that surrounds the World.

I ne'er was blest with sight of thee till now,

1) Works II, p. 3 ff. $\quad$ 2) Works I, p. 284 ff. $\quad$ s) Works III, p. 88.

4) Epilog, Works III, p. 162: 'T is a slight Farce, five Days brought forth.

5) Die gemahlin des puritanergenerals Lambert. ${ }^{6}$ ) Works I, p. 338. 
But in much reverenc'd Pictures - [Rises and bows].

There's such Divinity i' th' very Form on 't,

Had I been conscious I 'd been near the Temple,

Where this bright Relick of the glorious Martyr (Karl I.)

Had been enshrin'd, 't had spoil'd my soft Devotion.

- ' $T$ is Sacrilege to dally where it is;

A rude, a saucy Treason to approach it

With an unbended knee: for Heav'ns sake, Madam,

Let us not be profane in our Delights,

Either withdraw, or hide that glorious Object.

I)as lustspiel, das voll ist von lasciven scenen, schliesst mit den frommen worten: ${ }^{1}$ )

Then let 's all home, and to the Powers Divine

Pray for the King, and all the sacred Line.

Mit den letztgenannten lustspielen findet die dramatische thätigkeit Aphra Behns einen vorläufigen abschluss. Die gründe dafür lagen, wie wir schon gezeigt haben, in den zeitverhältnissen. Es trat eine allgemeine reaktion nach der einseitigen betonung des dramas ein, über die nicht nur Aphra Behn, sondern auch andere dichter, z. b. Dryden, klagen. ${ }^{2}$ ) Durch den mangel an teilnahme der leute an dem theater wurde Aphra Behn gezwungen, ihren unterhalt durch arbeiten auf andern litterarischen gebieten $\mathrm{zu}$ erwerben. Sie wandte sich der lyrik und novellistik zu. Die zeit zu beginn der achtziger jahre muss für unsere schriftstellerin sehr ernst gewesen sein. Ausser den klagen in den prologen und epilogen iiber mehr materielle sorgen scheinen sie auch traurige gemïtsstimmungen verstimmt zu haben, wie ein gedicht, betitelt "T'o Mrs. W. On her Excellent Verses (Writ in Praise of some I had made on the Earl of Rochester). ${ }^{3}$ ) Written in a Fit of Sickness", bezeugt. Da der tod des grafen Rochester in das jahr 1680 fällt, so muss das gedicht in dem genannten jahre oder darauf entstanden sein. Vielleicht bewog Aphra Behn das schicksal Rochesters, der im schönsten mannesalter den folgen eines ausschweifenden lebens erlegen war, zu den

1) Works I, p. 359 .

2) In dem prolog zu dem behnschen lustspiel The Widow Ranter, works IV, p. 106.

3) Diese verse, worauf A. B. hier anspielt, stehen in The Poetical Works of the Earls of Rochester, Roscomon etc., p. LXVI, und sind überschrieben On the Death of the Earl of Rochester. By Mrs. A. Behn. 
ernsten gedanken und melancholischen betrachtungen, die in dem gedicht enthalten sind. Daraus spricht ein gefühl der einsamkeit und trauer, das in grellem gegensatz $\mathrm{zu}$ der frivolen laune der lustspiele steht. ${ }^{1}$ )

Im jahre 1683 sammelte Aphra Behn ihre gedichte und gab sie ein jahr darauf heraus unter dem titel: „Poems upon Several Occasions", 1684. In demselben jahre veröffentlichte sie auch ihre erste novelle: "The Adventure of the Black Lady". ${ }^{2}$ ) In den nächsten jahren folgten nun noch andere gedichte, erzählungen und übersetzungen; zunächst 1685 eine zweite sammlung von gedichten verschiedener autoren, $u$. a. von Sir George Etherege, Henry Crisp, Aphra Behn selbst etc. ${ }^{3}$ ) Den tod Karls II. beklagte die schriftstellerin in einem Pindarick Poem. ${ }^{4}$ ) - Auf Karl II. folgte sein bruder Jakob (II.), der herzog von York. Die toryistisch gesinnten dichter hofften, dass der neue fürst die erwartungen, die man in bezug auf die unterstützung der kunst und ihrer jünger von Karl II. vergebens gehegt hatte, erfüllen würde. Auch A. Behn versuchte noch einmal ihr glück und veröffentlichte zwei lustspiele: "The Emperor of the Moon" ${ }^{5}$ ) und „The Lucky Chance, or, an Alderman's Bargain", ${ }^{6}$ ) beide 1687 gedruckt. Von interesse ist der epilog zu dem ersten stück. In demselben klagt die dichterin wieder über die geringe anteilnahme und unterstütznng von seiten des publikums, dem nichts recht zu machen sei, und wendet sich dann an den könig: ${ }^{7}$ )

Look back on flourishing Rome, ye proud Ingrates, And see how she her thriving Poets treats:

Wisely she priz'd 'em at the noblest Rate, As necessary Ministers of the State, And Contributions rais'd to make 'em great. They from the publick Rank she did maintain, And freed from Want, they only writ for Fame. Not Rome in all her happiest Pomp cou'd show A greater Caesar than we boast of now; Augustus reigns, but Poets still are low. May Caesar live, and while his mighty Hand Is scattering Plenty over all the Land; With God-like Bounty recompensing all,

1) Das gedicht steht in Poems von 1684, p. 57. 2) E. Gosse, a. a. 0.

3) Biogr. Brit. sub Behn. 4) E. Gosse, a. a. 0.

s) Works IV, p. 189 ff. ${ }^{\text {क) }}$ Works III, p. 164 ff. $\quad$ ') Works IV, p. 256. 
Some fruitful drops may on the Muses fall;

Since honest Pens do his just cause afford

Equal Advantage with the useful Sword.

Auch in dem prolog 1) des anderen lustspiels begegnen uns die bekannten klagen. Diese anspielungen beweisen, dass der versuch zu einer neuen dlramatischen thätigkeit bei Aphra Behn nicht mit erfolg gekrö̈nt war. Die schriftstellerin veröffentlichte denn auch keine dramen mehr, sondern sie schrieb prosaerzählungen und übersettzungen. Im jahre 1688 erschienen die beiden besten prosawerke Aphra Behns, "The History of the Royal Slave (Oroonoko)" und "The Fair Jilt"; ein jahr darauf zwei kleinere novellem, "The History of the Nun, or, the Fair Vow-breaker" und "The Lucky Mistake"..2) Diese veröffentlichungen waren die letzten litterarischen thaten Aphra Behns. Am 16. Aprill des jahres 1689 setzte der tod der unermüdlichen thätigkeiit der schriftstellerin ein ende. ${ }^{3}$ ) Aphra Behn wurde in der Westminster-Abtei beigesetzt. ${ }^{4}$ ) Auf dem schwarzen marmorsstein über ihrem grabe findet sich folgende inschrift: ${ }^{5}$ )

Mrs. Aphra Behn died Aprill the 16, 1689.

Here lies a proof that wit can never be

Defence enough a!gainst mortality.

Great Poetess, $O$ thy stupendous lays

The world admires, and the Muses praise.

Revived by Thomas Waine in respect to so bright a genious.

Nach ihrem tode wurden noch zwei unveröffentlichte dramen herausgegeben: "T'he Widow Ranter, published by one G. J. her Friend", ${ }^{6}$ ) worzu Dryden einen prolog dichtete, und "The Younger Brother" mit einem prolog „by an unknown Hand". ${ }^{7}$ )

Der vollständigkeit hallber muiissen hier noch die uibersetzungen, resp. bearbeitungren Aphra Behns genannt werden.

1) Works III, p. 164.

2) Langbaine, a. a. o.; the Fiair Vow-breaker ist uns leider nicht erhalten; ebenso habe ich nichts übrer die Love Letters between a Nobleman and his Sister, in three Volumes, JLondon 1684, die Langbaine als ein werk A. B.s anführt, erfahren können.

s) L. and M., p. 72: . . her Dieath, occasion'd by an unskilful Physician.

4) Ebenda. 5) Biogr. Brit. 6) Works IV, p. $106 \mathrm{ff}$.

?) Works IV, p. $341 \mathrm{ff}$. 
Im jahre 1680 lieferte die dichterin einen beitrag $\mathrm{zu}$ dem werke „Ovid's Epistles, translated by several Hands, with the Addition of three Epistles etc.; London 1680." ") Von Aphra Behn stammt das gedicht "A Paraphrase on Ovid's Epistle of Oenone to Paris", das sie in die sammlung ihrer gedichte von 1684 aufgenommen hat. In dieser sammlung steht auch die bearbeitung eines französischen werkes, welches heisst: "Le voyage de l'isle de l'amour, à Licidas; par Paul Tallemant, Paris 1663, zweiter teil 1664." 2) In diesem werke berichtet Lisander an seinen freund Licidas von seiner reise nach der insel der liebe und von seinen erlebnissen auf derselben. Die schrift ist eine gekünstelte allegorie in preziösem stil, die an abgeschmacktheiten wie die carte de tendre des fräulein von Scudéri erinnert; sie ist teils in prosa, teils in versen abgefasst. Aphra Behn hat in ihrer iibersetzung auch die prosa in verse verwandelt und hier und da erweitert, ohne aber etwas neues hinzuzubringen. Dieser übertragung folgt 1686 eine ähnliche bearbeitung eines anderen preziösen französischen werkes, betitelt „La Montre; par Monsieur de Bonnecorse; à Cologne, 1666; seconde partie, contenant La Boëte, et Le Miroir, à Paris 1671." Es ist gleichfalls in einer mischung von prosa und versen abgefasst. Aphra Behn hat hier die prosa nicht in verse gebracht, aber die verse vielfach wieder erweitert, sodass man das ganze eher als eine bearbeitung als eine übersetzung ansehen kann. ${ }^{3}$ ) Die übertragung des zweiten teiles durch Aphra Behn erschien erst 1697. ${ }^{4}$ )

Mit den beiden erzählungen "Oroonoko" und "The Fair Jilt" veröffentlichte Aphra Behn eine novelle "The History of Agnes des Castro". ${ }^{5}$ ) Die schriftstellerin giebt sie selbst

1) Lowndes, a. a. 0. III, p. 1746.

2) Siehe auch Recueil de quelques pieces nouvelles et galantes, Paris 1684 und 168j, vol. I u. II (nicht II u. III, wie Langbaine angiebt).

3) Nach meiner ansicht ist die ausführliche besprechung, die Beljame diesem werke in seinem schon erwähnten buche zuteil werden lässt, nicht am rechten ort; denn es ist ein französisches werk, gehört also in eine französische litteraturgeschichte; nicht der englischen dichterin, sondern dem französischen autor sind die „albernheiten" und „abgeschmacktheiten" vorzuwerfen; allerdings heisst sie Aphra $B$. auch gut, indem sie sie übersetzt.

4) Beide teile finden sich in Works VI, p. $73 \mathrm{ff}$.

5) Works VI, p. 1 ff. 
als ihr werk aus, und man hielt dieselbe auch immer für ein selbständiges werk Aphra. Behns. Allein es ist nichts weiter als eine wörtliche übersetzung der französischen novelle „Agnès de Casto, Nouvelle Portugaise; par M ${ }^{\text {lle } * * * * * *}$ (J. B. de Brilhac); a Amsterdam, 1688." Eine andere übersetzung aus dem Französischen, „Lycidas, or, the Lover in Fashion, 1688", 1) ist uns nicht erhalten. Ebenso war es unmöglich, drei andere übersetzungen ausfindig zu machen, nämlich „Rochefoucaulds Réflexions morales" unter dem titel "Seneca Unmasked“, 2) „Fontenelles Entretiens sur la pluralités des mondes, 1688“3) und endlich "The History of Oracles des Holländers Van Dale, 1699“,4) jedenfalls nach der französischen übertragung von Fontenelle, die 1687 erschien. ${ }^{5}$ ) Endlich ist noch zu erwähnen, dass Aphra Behn ein lateinisches werk des englischen dichters Cowley übersetzte, und zwar das sechste buch von Cowleys werk "Of Plants". ${ }^{6}$ )

\section{II. Aphra Behns gedichte.}

Die gedichte Aphra Behns ragen zwar nicht über diejenigen der zeitgenossen hervor, allein sie bilden doch einen charakteristischen teil des poetischen schaffens der schriftstellerin, sodass es geboten erscheint, dieselben in den kreis unserer betrachtung zu ziehen.

Aphra Behn gab ihre gedichte 1684 heraus; ausserdem finden sich einige in der 1685 veröffentlichten anthologie, wie wir oben gesehen haben. ${ }^{7}$ ) Die folgende betrachtung stützt sich auf die wichtigste ausgabe vom jahre $1684 .{ }^{8}$ ) Die ge-

1) Langbaine, a. a. o. $\quad$ 2) Biogr. Brit. s) Biogr. Brit.

4) Sharp, a. a. o. ") Höfer, a. a. o. XVIII, p. 126.

6) The Poetical Works of Abraham Cowley. In Four Volumes. Edinburg. Anno 1777. Vol. IV, p. 5 ff.: Of Plants. Book VI: Of Trees. Translated by Mrs. A. Behn. Es ist jedenfalls dieselbe übersetzung, die Hazlitt verzeichnet; cf. Carew Hazlitt, Collections and Notes. 1867-1876. London 1876. p. 106, sub Cowley: A Translation of the Sixth Book of Mr. Cowley's Plantarum. Being a Poem upon the late Rebellion, the Happy Restoration of his Sacred Majesty, and the Dutch War Ensuing ... London 1680.

$\left.{ }^{7}\right)$ p. 106. Gerade in bezug auf die gedichte macht sich der mangel an zugänglichen ausgaben unliebsam geltend; die originalausgaben sind schwer erreichbar, und in die "Works" sind die gedichte leider nicht aufgenommen; die ausgabe von 1685 ist mir nicht zugänglich gewesen.

8) Abgekürzt "Poems 1684“. 
dichte sind gewidmet "to the Right Honourable, James, Earl of Salisbury, Viscount Cramborn, and Baron of Islington. 1) Abgeschlossen muss die sammlung schon 1683 gewesen sein, denn ein lobgedicht auf Aphra Behn, das mit noch mehreren anderen den Poems 1684 voransteht, ist datiert vom 25. November 1683. ${ }^{2}$ ) Die entstehung der einzelnen gedichte erstreckt sich über eine reihe von jahren. Als sicher können wir feststellen, dass Aphra Behn schon vor 1671 verse geschrieben hat, denn schon in ihrem ersten drama findet sich eins ihrer besten gedichte. ${ }^{3}$ ) Auch in den meisten anderen dramen sind gedichte eingestreut, wovon mehrere in die Poems 1684 aufgenommen sind.

Die dichterin scheint ursprünglich nicht die absicht gehabt zu haben, ihre gedichte zu veröffentlichen. Dafür spricht einmal die geringe anzahl derselben, noch mehr aber eine äusserung in dem Epistle Dedicatory, welche lautet: „Be pleased then, my Lord, to accept this Little Piece, which lazy Minutes begot and hard Fate has oblig'd me to bring forth into the censuring World." Was wir unter dem "hard Fate“, das sie zur veröffentlichung der gedichte zwang, zu verstehen haben, lässt sich mit wahrscheinlichkeit vermuten. Wir haben oben (p. $106 \mathrm{f}$.) gesehen, dass die dramatische thätigkeit eine beschränkung erlitten hatte. Dies musste für Aphra Behn auch eine pekuniäre einbusse bedeuten, die sich wohl um so fühlbarer machte, als die dichterin von einer krankheit heimgesucht worden war. Durch die herausgabe der gedichte wollte sie jedenfalls ihrer pekuniären lage aufhelfen.

Die angeführte stelle aus dem Epistle Dedicatory deutet auch an, wie und zu welchem zwecke die gedichte entstanden. Abgesehen werden muss hierbei von den liedern, die schon deshalb, weil sie in dramen stehen, für die öffentlichkeit be-

1) Cecil, James, fourth Earl of Salisbury, gestorben 1693; cf. D. N. B. IX, p. 397.

2) To Mrs. Behn, On the Publishing her Poems; by J. Cooper.

s) Love Arm'd, Poems 1684, p. 45 . Dasselbe gedicht steht auch in Chambers's Cyclopædia etc. I, p. 325; ferner, ohne nennung der verfasserin, in The Loyal Garland: A Collection of Songs of the Seventeenth Century, Reprinted from a Black-Letter Copy Supposed to be Unique. Ed. by J. 0 . Halliwell. London 1850, Percy Society. Vol. XXIX, p. 7 unter dem titel: Tyrannick Love, or, The Cruel Mistress. 
stimmt waren; sie sollten zur lbelebung der theaterstücke dienen. Dies gilt aber durchaus nichit von der hauptmasse der Poems 1684. Aphra Behns hauptsïächlichste dichterische thätigkeit bewegte sich zunächst auf de?m gebiete der dramatischen kunst. Die gedichte sind nur nebenbei entstanden; sie sind erzeugnisse müssiger stunden (of lazy hours), kleinigkeiten (little pieces), die für einen intimen kreis brestimmt waren. Das versemachen gehörte in den feinen kreisem zum guten ton; es war ein gesellschaftliches unterhaltungssspiel, dem sich niemand, der für einen schöngeist („Wit") gellten wollte, entziehen durfte, und bei dem man sich gegenseittig mit schmeicheleien bekomplimentierte oder seine fingierte liebespein klagte. Aphra Behn hat sicher einer der schöngeisttigen, galanten salongesellschaften, der sogenannten coteries, dice man nach französischem muster einrichtete, angehört. Sie seelbst giebt in einem gedicht „Our Cabal" ') galante beschreibuungen, ähnlich den bekannten porträts, der einzelnen mitgllieder, natürlich unter namen, die man sich nach berühmten uromangestalten beilegte. ${ }^{2}$ ) Diese namen kehren fast alle in den einzelnen gedichten wieder, sodass wir sehr wohl annehmien können, dass letztere für einen bestimmten kreis geschrieben waren. Diese gesellschafts- oder salonpoesie, wie wir die gredichte Aphra Behns bezeichnen können, hat die englische litteratur aus Frankreich übernommen. Es ist die galante poesie, unter deren einfluss die bedeutendsten dichter der restaurationszeit, Dryden, Waller, Philips, etc., standen.

Der stoffkreis, in dem sich diese gedichte bewegen, ist kein grosser. Die liebe, wite sie in einer äusserlich galanten und gezierten, innerlich friivolen und lüsternen gesellschaft herrscht mit ihrer lust und ihrem schmerz, ist zum grössten teil der anlass und inhalt der gedichte Aphra Behns. Sie sind nach der sitte der zeit inı das gewand schäferlicher idylle gekleidet, wodurch sie von vornherein etwas geziertes, unnatürliches für uns erhalteni. - Gehen wir etwas näher auf den inhalt ein. An der spittze der sammlung steht eine langatmige ode, die uns in das milieu einführt, in welchem sich

1) Poems 1684, p. 33

2) Z. b. Alexis, Damon, Amorret, Thyrsis, Amyntas, Philocless, Phillis, Lysidas, Philander etc. 
die meisten gedichte bewegen; sie ist betitelt: "The Golden Age. A Paraphrase on a Translation out of French." Ein ewiger frühling mit wolkenlosem, lachendem himmel und immerblühenden, duftenden blumen in stillen hainen herrschte einst auf der erde. An den ufern der murmelnden flüsse lagen noch nicht liebekranke schäfer und nymphen, um die pein unglücklicher liebe $\mathrm{zu}$ bejammern. Junge zephire fächelten sich sanfte lüfte zu. Die bewohner der schattigen haine konnten sich ungestört dem zarten spiel der liebe und dem genusse sanfter musik hingeben. Die rauhen töne des kriegs erschreckten die welt nicht. Tyrannische könige erliessen keine gesetze, um sie selbst zu brechen, und keine götter narrten die erdbewohner mit religionen. ${ }^{1}$ ) Jeder war sein eigner herr; die unschuld war religion und gesetz. Recht und eigentum waren unbekannte begriffe; das gut gehörte der gemeinschaft. Ehrgeiz, stolz, ruhmsucht und alle die anderen leidenschaften des menschlichen herzens streuten ihr gift noch nicht aus. Vor allem aber war es eine goldene zeit der liebe, denn diese war frei und noch nicht an strenge, eheliche gesetze gebunden, die erst von gelehrten, langweiligen narren erfunden wurden. Die ausführung des letzteren gedankens nimmt in bezeichnender weise über die hälfte des gedichtes in anspruch. Gleich das nächste gedicht, „A Ballad on $\mathrm{Mr}$. J. H. to Amoret, asking why I was so sad", ${ }^{2}$ ) handelt von der liebe der modernen zeit. Astrea (-A. B.) ist so traurig, dass ihre freundin Amoret sie nach der ursache ihres kummers fragt. Da erzählt ihr Astrea, wie sie bei einem tanzfest im schatten des haines den hirten Anyntas gesehen hat. $\mathrm{Fr}$ wandelte wie der herr des Maies unter den hirtinnen und hirten, die ihre herden auf dem plane weideten. Sein herrlicher körper war geschmïckt mit feinen kleidern, auf deren ärmeln rote liebesbänder gestickt waren. An der seite hing ilhm eine silberne brieftasche. Das schönste und gefährlichste an ihm aber waren seine augen, mit denen er die herzen aller nymphen verwundete. Dabei konnte er sich verstellen, um dadurch nur desto sicherer sein ziel zu erreichen :

1) The Gods by teaching us Religion first, first set the World at odds.

2) Poems 1684, p. 29. 
He well cou'd feign an Innocence,

And taught his Silence Eloquence;

Each Smile he us'd, had got the force,

To conquer more than soft Discourse:

Which when it serv'd his Ends he'd use, And subtily thro' a heart infuse.

Ueber alles erhaben aber war sein witz, mit dem er alles durchschaute und vor dem keine einwürfe gegen die liebe bestehen konnten. Mit allen diesen reizen begegnete Amyntas den verliebten hirtinnen. Und wie die hirtenflöte ihr spiel begann und der liebliche schäfer Astrea zum tanz aufforderte, da bemühte sie sich vergebens, ihr herz seinen zärtlichen seufzern und flehenden augen $\mathrm{zu}$ verschliessen: Ehe die eintretende nacht der lustbarkeit ein ende bereitete, war Astrea gänzlich "verloren und gewonnen“. Und nun ist sie melancholisch und traurig, und sie warnt Amoret vor den unwiderstehlichen reizen des eroberers Amyntas. - Doch es bleibt nicht immer nur bei einer traurigen gemütsstimmung; die wirkungen der allgewaltigen liebe sind meist tragischer. So legt sich Amyntas an das ufer eines flusses und klagt den mitleidigen fluten sein schweres leid:1) Die reizende falsche Sylvia wendet anderen ihr lächeln und ihre küsse zu, die sie ihm schuldig ist, und achtet nicht seines schmerzes. Das echo selbst hat mehr mitgefühl mit seinem kummer, denn es wiederholt seine klagerufe. Ein andermal liegt der schäfer wieder am flussufer, wo er eine solche menge thränen über Sylvia's "cold Disdain“ vergiesst, dass die fluten anschwellen. ${ }^{2}$ ) $\mathrm{Er}$ ruft die schatten des haines zu zeugen ihrer falschen schwüre an, die sie mit demselben atem gesprochen, mit dem sie jetzt sein todesurteil ausspricht - denn nur der tod kann solch schreckliche liebesschmerzen enden. Ehe der hirte aber stirbt, prophezeit er Sylvia fürchterliche rache: Zerbrechen wird er sein grab und der untreuen zur mitternacht als geist mit blutender brust, den wunden der liebe, erscheinen. - Natürlich beklagt auch umgekehrt die hirtin oder nymphe sich über den grausamen schäfer. Die arme Serena sitzt ebenfalls am flussufer und betrauert ihr hartes schicksal. ${ }^{3}$ ) Ihr kummer ist zu

1) Song. The Complaint. Poems 1684, p. 46.

2) Song. To Pesibles Tune. Poems 1684, p. 86.

8) The Reflection. A Song. Poems 1684, p. 83.

Anglia. N. F. XIII. 
gross, als dass er sich in einer flut von seufzern und stummen thränen auflösen könnte; "she must speak or dye“. Die dichterin lässt nun Serena sich ihres schicksals erinnern: Sie muss denken an alle die mittel - die sanften reize der beredsamkeit, die blicke der augen, die eine stille sprache der liebe redeten, die schmeicheleien, an denen ihre lauschende seele hing, die geschenke, die lieder, der geist - mit denen der untreue schäfer ihre kalte zurückhaltung und die scheue unschuld ihrer seele überwand. Doch je mehr sie ihm gab, je mehr er die entzündeten flammen in ihr anfachte, um so kälter ward seine glut, bis er ihr die treue brach. - Auch den schmerz des abschieds kleidet Aphra Behn in witzige verse. Jemmy, der lustigste und lieblichste schäfer, mit dem sie oft auf der weide getändelt hat, vertauschte seinen hirtenstab mit dem schwert und liess seine nymphe einsam und trauernd zurück. 1) Allerdings scheint Jemmy in seinen ehrgeizigen plänen herbe enttäuschung erlitten $z u$ haben, denn in einem andern gedicht ${ }^{2}$ ) beklagt er es bitter, dass er die idyllische ruhe seines schäferlebens aufgegeben habe, und warnend ruft er seinen jugendgenossen $\mathrm{zu}$ :

\section{Ye noble Youths beware, \\ Shun ambitious powerful Tales: \\ Distructive, false and fair, \\ Like the Ocean's flattering gales, \\ Like blasted Flowers i' th' Spring.}

Ein beliebtes thema der gedichte ist auch der gedanke, dass die liebe sich nicht ungestraft beleidigen lasse. Niemand vermag ihr $\mathrm{zu}$ entrinnen, und wer sie verachtet oder sich ihr zu entziehen strebt, verfällt einem schlimmen geschick. So glaubte Phillis $^{3}$ ) berechtigt $\mathrm{zu}$ sein, alle huldigungen der schäfer spröde zurückweisen zu können; keine seufzer und thränen vermochten ihr kaltes herz zu rühren. Da erblickte sie eines tages den schäfer Strephon, der im schatten des haines schlief. Sogleich ergriff ihr herz ein ungewöhnlicher schmerz; die liebe hatte sie verwundet; aber vergebens flehte sie nun die wälder und das echo um linderung ihrer liebes-

1) Song. Poems 1684, p. 84 .

2) Song. To a new Scotch Tune. Poems 1684, p. 123.

s) Song. The Surprize. Poems 1684, p. 91. 
qual an. Ebenso erging es Celinda; 1 ) auch sie verachtete die liebe, bis sie auf der weide einen schönen hirten sah:

At first she laught, but gaz'd the while, And soon she lessen'd to a Smile;

Thence to Surprize and Wonder came, Her Breast to heave, her Heart to flame:

Then cry'd she out, Now, now I prove, Thou art a God, Almighty Love.

Während die bisher besprochenen gedichte mit ausnahme des einen (A Ballad on Mr. H., p. 112 f.) sich wenig auf die person der dichterin selbst beziehen, sind die folgenden subjektiver, weshalb sie schlüsse auf galante abenteuer der autorin zulassen. Es betrifft dies vor allem vier gedichte, die fast unmittelbar aufeinanderfolgen. Aus dem ersten, „To Lysander, who made some verses on a Discourse of Loves Fire", ${ }^{2}$ ) geht hervor, dass Astrea eine tiefe zuneigung zu Lysander gefasst hat. Allein eine andere hirtin, Amynta, hat schon vorher Lysanders herz entzündet. Trotzdem begehrt Lysander von Astrea befriedigung seiner wünsche; letztere will jedoch eher sterben, als die „known and sacred Laws of Love" übertreten,

For 'tis a Maxime in Love's learned School,

Who blows the Fire, the Flame can only rule.

Aber Lysander lässt sich scheinbar dadurch nicht zurückschrecken, sondern er geht sogar noch weiter, worauf sie ihn nochmals zurückweist in dem gedicht "To Lysander, on some Verses he writ, and asking more for his Heart, then 'twas worth. ${ }^{3}$ ) Sie beklagt sich, dass er trotz seiner liebesbeteuerungen schon wieder eine andere, nämlich Adraste, liebe, worüber ihre eifersucht entbrennt:

Whilst like a glimering Taper still I burn,

And waste my self in my own Flame,

Adraste takes the welcome rich Return:

And leaves me all the hopeless Pain.

Im dritten gedicht erzählt Astrea, wie sie Lysander bei einem Musick-Meeting ${ }^{4}$ ) gesehen hat. Dieses gedicht ist für

1) Love reveng'd. A Song. Poems 1684, p. 122.

2) Poems 1684, p. 101

s) Poems 1684, p. 109.

-) To Lysander at the Musick-Meeting. Poems 1684, p. 118. 
die ganze art der beschreibung und ausmalung charakteristisch, sodass es hier teilweise folgen möge:

I saw the Softness that compos'd your Face, While your Attention heighten'd every Grace:

Your Mouth all full of Sweetness and Content, And your fine killing Eyes of Languishment:

Your Bosom now and then a Sigh wou'd move, (For Musick has the same Effects with Love.)

Your Body easy and all tempting lay, Inspiring Wishes which the Eyes betray, In all that have the Fate to glance that way:

A careless and a lovely Negligence,

Did a new Charm to every Limb dispence:

So look young Angels, listening to the Sound, When the tun'd Spheres glad all the Heav'ns around:

So raptur'd lie amidst the wondering Crowd, so charmingly extended on a Cloud.

Solchen reizen vermochte Astrea nicht zu widerstehen, besonders

Since Harmony, like Fire to Wax, does fit

The softned Heart Impressions to admit.

Das vierte hierher gehörige gedicht endlich ist überschrieben: "An Ode to Love". ") Es ist nicht etwa eine verherrlichung Amors, sondern Lysanders. Die dichterin fordert die liebe, die stets personifiziert erscheint, auf, bogen und pfeile zu zerbrechen; denn diese nützen doch nichts mehr, seitdem die augen Lysanders alle herzen verwunden. Ein gott selbst, der sich an dem gott der liebe rächen wollte, hat den reizenden jüngling Lysander in einer glücklichen stunde geschaffen und ihn mit göttlichen kräften ausgestattet. Die dichterin bleibt aber vor lauter witzigen und geistreichen einfällen nicht logisch in der fortführung des gedichtes. Denn obgleich die liebe nach der aufforderung zu anfang des gedichtes noch im besitze von bogen und pfeilen sein muss, wird doch in den folgenden strophen erzählt, dass Lysander dem liebesgott, als dieser im schatten der myrte schlief, die waffen raubte. Gerade in diesem gedicht macht sich die sucht, möglichst geistreich und pointiert zu dichten, unliebsam bemerkbar, indem sie die klarheit stört. Der zweck liegt klar zu tage: es ist eine schmeichlerische huldigung für den geliebten. Die galanterieen gehen

1) Poems 1684, p. 120. 
herüber und hinüber. So erhält Astrea eines morgens, als sie noch im bett liegt, ein huldigungsgedicht von Amyntas, das dieser im traume verfasst hat. Ganz entzückt darüber preist sie nun ihrerseits den „witz" des galanten schäfers in überschwänglichen versen. ${ }^{1}$ ) Dann wieder bringt sie einen brief von Amyntas in verse ${ }^{2}$ ) und schickt ihm eine poetische antwort. ${ }^{3)}$ Auch andere zarte aufmerksamkeiten ihres schäfers begeistern Astrea zum dichten. So schreibt sie ein weitschweifiges gedicht über „eine in einen liebesknoten verschlungene haarlocke"..4)

Die veranlassungen und ursachen, die Aphra Behn zum dichten begeisterten, sind, wie wir sehen, nicht besonders tiefer art. Es ist eine gezierte, tändelnde poesie, die auf uns den eindruck der geschraubtheit macht. Aber diese ganz unlyrische lyrik war die modepoesie zu der zeit Aphra Behns. Waller, einer der angesehensten dichter jener zeit, auch Dryden haben gedichte derselben art in menge geschrieben.

Weit schöner als diese gezierten, galanten gedichte muten uns diejenigen an, die wir als horazisch-anakreontische bezeichnen können. Damit sind die gedichte gemeint, die einer sinnlich-heiteren lebensauffassung entspringen und im verhältnis zu den besprochenen sentimentalen, idyllisch-manierierten gedichten natürlicher und frischer erscheinen. Sie sind zwar auch mit dem schäferlichen gewand umgeben - die personen sind auch hirten und hirtinnen., die situation bewegt sich auch in schattigen hainen und an murmelnden flïssen -, aber dieses gewand ist hier ganz äusserlich. Die menschen in diesen gedichten sind lebensfroh und erschöpfen sich nicht in rührseligen klagen oder umständlichen, schmeichlerischen huldigungen. Der inhalt dieser gedichte variiert meistens den gedanken, das leben müsse in der jugend genossen werden und um das ende dürfe man sich nicht kümmern. Anakreon und Horaz sind im altertum die hauptvertreter dieser genussfrohen richtung in der lyrischen dichtkunst. Beide wurden unter den antiken dichtern neben Virgil und Ovid in der englischen

1) On a Copy of Verses, made in a Dream, and sent to me in a Morning, before I was awake. Poems 1684, p. 63.

$\left.{ }^{2}\right)$ The Sence of a Letter sent me, made into Verse. Poems 1684, p. 61.

s) The Return, Poems 1684, p. $62 . \quad$ 4) Poems 1684, p. 77. 
litteratur am meisten verehrt und nachgeahmt. Aphra Behn kannte diese dichter auch; sie hat selbst gedichte von Horaz und Ovid übertragen, bez. nachgeahmt. Ebenso musste ihr Anakreon bekannt sein, wenn auch jedenfalls nicht in der ursprache, da Cowley, dessen gedichte sie sehr hochschätzte, anakreontische gedichte übersetzt hatte. ${ }^{1}$ ) Während nun bei den gleichzeitigen dichtern liebe und wein in gleichem masse gefeiert werden, singt unsere dichterin nur den preis der liebe, zu deren genuss sie auffordert: ${ }^{2}$ )
A Pox upon this needless Scorn:
Sylvia for Shame the Cheat give o'er:
The End to which the Fair are born, Is not to keep their Charms in store:
But lavishly dispose in Haste
Of Ioys which none but Youth improve;
Ioys which decay when Beauty's past;
And who, when Beauty's past, will love?

Trotzdem die liebe das grundthema der gedichte Aphra Behns bildet, also ein echt lyrisches, so fehlt doch dieser poesie das eigentlich lyrische moment, das echte gefühl. Die auffassung der liebe ist äusserlich und oberflächlich, dabei aber charakteristisch für die zeit. Die liebe ist kein impulsives, tiefwurzelndes gefühl der hingabe, sondern eine verstandesmässige tändelei, die nichts mit wahrem gefühl $\mathrm{zu}$ thun hat, trotz des scheinbaren gefühlsuiberschwanges. Man disputiert über das feuer der liebe, schickt sich einander schmeichlerische gedichte und erweist sich sonst galante aufmerksamkeiten, um die tiefe seiner neigung zu beweisen. Je äusserlicher man die liebe auffasst, desto mehr worte werden verschwendet, um sie zu schildern. Ueberall begegnen wir der übertreibung. In überschwänglicher sentimentalität jammern die schäfer und nymphen; die lüfte sind mit einem übermass von seufzern erfüllt. Bei den mädchen rühren uns die klagen noch eher, und Aphra Behn findet wohl auch töne, die wirklichen gefühlen entspringen; ${ }^{3}$ ) um so feiger erscheinen die männer mit ihren thränenfluten und kindischen klagen. Die grosse rührseligkeit ist zum teil der thatsache zuzuschreiben, dass wir eine dichterin vor uns haben. Andererseits ist darauf hinzuweisen, dass gerade

1) Cowley, a. a. o. 2) The Counsel. Poems 1684, p. 89.

s) The Reflection, p. 113 unten. 
die sentimentalität in den beliebten idealromanen, dann vor allem in den romanen des 18 . jahrhunderts, ein charakteristisches merkmal ist. Wir werden nicht anzunehmen brauchen, dass es die unglücklich liebenden so ernst mit ihren erbarmungswürdigen klagen meinten und thatsächlich so schnell in den tod eilten, wie man nach ihren reden annehmen müsste. Es liegt vielmehr darin eine indirekte huldigung der oder des geliebten; die dichterin will in geistreicher weise zeigen, welche ungeheure macht die liebe besitzt, die die angebetete person einflösst. Diese schönrednerische tendenz steht in widerspruch zu dem gewählten milieu. Man kann sich kaum einen grösseren gegensatz denken als denjenigen zwischen den schöngekleideten, geistreichen, in allen feinen und galanten künsten erfahrenen "schäfern" und einer wirklich naiven, bedürfnislosen, natürlichen hirtenwelt. Dieser gegensatz wirkt um so greller, als wir uns unter den sentimentalen, gezierten schäfern und hirtinnen sinnliche genussmenschen des restaurationszeitalters, die sich an den sittenlosesten, rohesten komödien ergötzten, zu denken haben. Ihr wahrer charakter kann sich trotz des künstlichen gewandes der unschuldigen idylle nicht verleugnen. Auch in diesen zärtlichen, "verliebten" gedichten blickt sehr oft die frivolität hervor, die in den lustspielen so offen und frech ihr haupt erhebt. Gerade durch die hülle scheinbarer naivetät müssen die gedichte um so pikantere wirkung bei der feinen leserwelt ausgeübt haben. Ein beispiel dafür haben wir schon oben kennen gelernt. 1) Die pikante schilderung der äusserlichen reize des geliebten sind darauf berechnet, sinnliche erregung hervorzurufen; geradezu abstossend muss es auf uns wirken, wenn die dichterin dabei noch eine fromme miene aufsetzt, indem sie vergleiche mit unschuldigen engeln zieht. Doch oft bemüht sich die dichterin nicht einmal, wenigstens äusserlich den schein der guten sitte zu bewahren; sie scheut sich nicht vor kecken, lüsternen andeutungen und schlüpfrigen detaillierten schilderungen. Es finden sich bei Aphra Behn gedichte, welche zu lesen eine gesittete frau sich schämen würde. ${ }^{2}$ ) Es ist auch darin keine entschuldigung $z u$

1) Siehe p. 116.

2) On a Juniper-Tree cut down to make Busks. Poems 1684, p. 19; The willing Mistress, a. a. 0. p. 44; The Disappointment, a. a. 0. p. 70. 
sehen, dass gerade die beiden bedenklichsten gedichte möglicherweise nicht von Aphra Behn sind ;') denn dadurch, dass sie dieselben in ihre sammlung aufgenommen hat, giebt sie ja ihre billigung zu erkennen. Allerdings müssen wir auch hier auf die moralisch zerrütteten verhältnisse der zeit rücksicht nehmen. Es gab auch in Deutschland zu jener zeit dichter, welche in ihrer poesie in bezug auf frivolität und unmoral der Engländerin nichts nachgeben; gerade eins der schlüpfrigsten gedichte Aphra Behns wurde ins Deutsche übertragen. ${ }^{2}$ ) Die frivolität ist mehr oder weniger ein charakteristikum der leichten, galanten poesie. Aphra Behn bewegt sich auch sonst innerhalb der grenzen dieser dichtungsart. Die wirkungen der liebe werden durch die üblichen mittel geschildert: schnelles erröten, zärtliche seufzer, schmachtende augen, sentimentale klagen etc. Die liebe erscheint stets personifiziert als „God of Love" oder einfach als "Love“, ausgerüstet mit bogen und pfeilen, mit denen sie die herzen der menschen verwundet. Eine ganz besondere macht wird den augen zugeschrieben. In ihnen spiegelt sich die seele und sie geben die sprache des herzens wieder:

My wounded Soul mounts to my Eyes,

As it would prattle Stories there. ${ }^{3}$ )

Auch das streben nach „witzigen“, d. h. pointierten, durch ihren antithetischen sinn überraschenden gedanken und aussprüchen kennzeichnet die behnsche lyrik. So flösst die erscheinung des geliebten sowohl furcht wie wünsche ein: „I at once both wish and fear" ${ }^{4}$ ) oder der verschmähte schäfer klagt den göttern, dass in der falschen nymphe himmel und hölle vereinigt sind, ${ }^{5}$ ) und von dem trefflichen Amyntas heisst es gar: ${ }^{6}$ )

You do not only kill at sight,

But like a Parthian in your Flight;

Wether you rally or retreat,

You still have Arrows for Defeat.

Mythologische anspielungen, vergleiche mit gestalten aus der antike, die in der galanten poesie sehr beliebt sind, finden sich zwar auch bei Aphra Behn, aber nur in geringem masse;

') Siehe p. $126 \mathrm{f} \quad \quad 2$ ) Siehe p. 128.

3) Song. Poems 1684, p. 92 . 1) Ebenda.

5) Song. To Pesibles Tune. Poems 1684 p. $\left.86 .{ }^{6}\right)$ Siehe p. 117, a. 1. 
sie war doch nicht so bekannt mit dem klassischen altertum wie ihre männlichen kollegen. Dagegen ist in ihrer poesie ein anderes element besonders ausgebildet, die beseelung der natur mit menschlichen empfindungen und gefühlen. Allerdings ist die betrachtung der nattur ganz konventionell. Die natur ist für die dichterin - daurin berührt sie sich gleichfalls wieder eng mit der galantem dichtung - nur ein mittel zum zwecke, nicht der endzweck selbst. Sie ist nicht das höchste vorbild für den menschen, sondern sie steht unter diesem und ist verbesserungsfähig:. 1) In dem gedicht „On the Death of Mr. Grinhil, the famous Painter" ") rühmt die autorin von dem maler:

Great Master of the noblestt Mysterie,

That ever happy knowledge does inspire;

Sacred as that of Poetry

And which the wond'ring WWorld does equally admire.

Great Natures Work we: do contemn,

When on his glorious Birthus we meditate:

The Face and Eies, more D)arts receiv'd from him,

Than all the Charms shce can create.

The Difference is, his Beautties do beget

In the inamour'd Soul a verrtuous Heat:

While Natures grosser Piecees move,

In the coarse Road of common Love.

Was nun von der natur gezeiigt wird, das beschränkt sich in Aphra Behns gedichten auf blumige wiesen, schattige, dunkle haine und murmelnde kühle flüsses. Z $\mathrm{Z}$ diesen plätzen werden die liebenden mit vorliebe geführtt, um den blumen, bäumen und dem wasser ihr leid zu klagem, oder ihre lust zuzujubeln. Die bäume, blumen, quellen etc. 'verstehen auch die sprache der menschen; sie stellen sich in ihren dienst: $\left.{ }^{3}\right)$

Then with a Stream he (Daimon) holds Discourse:

0 thou that bend'st thy liquid Force

To lovely Thames! upon whose Shore

The Maid resides whom I ardore!

My Tears of Love upon thy Surface bear:

And if upon thy Banks thoiu seest my Fair:

In all thy softest Murmurs ising,

From Damon I this Present: bring;

$\left.{ }^{1}\right)$ Diese auffassung von der natur :steht im gegensatz zu derjenigen im Oroonoko, wo A. B. die natur als grö̈sste meisterin preist.

2) Poems 1684, p. $24 . \quad{ }^{3}$ ) La Momtre; works VI, p. 202 f. 
My e'ery Curl contains a Tear!

Then at her Feet thy Tribute pay:

But haste, Oh happy Stream! away;

Lest charm'd to much, thou shouldst for ever stay.

And thou, Oh gentle, murm'ring Breeze!

That plays in Air, and wantons with the Trees;

On thy young Wings, where gilded Sun-beams play,

To Iris my soft Sighs convey.

Diese beseelung der natur würde nicht unnatürlich, vielmehr belebend wirken, wenn sich die dichterin vor übertreibung hütete. Bei ihr wird diese belebung der natur nur ein mittel mehr zur verherrlichung der verehrten person. Aphra Behn geht darin so weit, dass sie Irland die glückliche insel mit ihren grünen wiesen und schönen blumen, mit ihren dunklen hainen und perlenden quellen, mit ihren wäldern und hügeln und wandernden bächlein beglückwünscht, dass "Celladon, the great godlike Celladon", ihr die gnade erweist, sie zu besuchen. ${ }^{1)}$ Ja die natur verhält sich nicht nur passiv, indem sie mit dem menschen fühlt und leidet und deren klagen anhört, sondern sie wird selbst von der macht der liebe ergriffen. Die sanften winde küssen die hängenden zweige; der wacholderbaum erzählt, dass, als sich Philocles und Cloris in seinen schatten gelagert hatten, er seine zweige so tief gebeugt hat, dass sie den schäfer küssen konnten. ${ }^{2}$ ) Diese „witzige“ art, die natur zu verwenden, findet ein sehr anschauliches beispiel in den folgenden versen aus dem gedicht „On Mr. J. H. In a Fit of Sickness" ${ }^{3}$ ) (d. h. J. H. = Amyntas ist krank, nicht Astrea):

Forsaken looks th'enameld May :

And all its Wealth uncourted dies;

Each little Bird forgets its wonted Lay

That sung good Morrow to the welcome Day,

Or rather to thy lovely Eies.

The cooling Streams do backward glide:

Since on their Banks they saw not thee,

Losing the Order of their Tide, And murmuring chide thy Cruelty:

Then hast to lose themselves i' th' angry Sea.

Wir miissen noch kurz auf die gelegenheitsgedichte Aphra Behns eingehen. Es sind einige huldigungsgedichte, die die

') A Farewel to Celladon, On his going into Ireland. 'Poems 1684, p. 13.

) On a Juniper-Tree etc. Poems 1684, p. $19 .{ }^{3}$ ) Poems 1684, p. 106. 
gefeierten in allen tonarten der schönrednerei preisen. Es sei besonders auf eins dieser gediichte, das wegen seines mutigen, aufmunternden tones sympathiisch berührt, hingewiesen: "To the Honourable Edward Howard, on his Comedy called the New Utopia“. 1) Aphra Behn ruft dem autor zu, wenn ihm auch von der menge nicht der verdiente beifall gezollt würde, so sei er dennoch unerreicht in seiner kunst, ja er übertreffe sogar den "mächtigen, grosssen Jonson". Sie fordert den dichter auf, sich nicht durch das ungünstige urteil der ungebildeten, beschränkten menge reinschüchtern zu lassen, sondern dem ansturm der missgünstigen zu trotzen und der blöden menge zu beweisen, dass er jihr nicht unterliege; denn auch der grosse Ben Jonson sei nur um so satirischer geworden, je mehr ihn die menge verurteilte. Wie sehr die dichterin die unwissende menge veraclhtet, mögen folgende verse aus dem besprochenen gedichte zejigen:

Your Soul of Thought you may imploy

A nobler Way,

Than in Revenge uppon a Multitude,

Whose Ignorance only makes 'em rude.

Should you that Justice do,

You must for ever lbid adieu,

To Poetry divince,

And ev'ry Mnse o' th' Nine:

For Malice then witth Ignorance would join,

And so undo thee World and you.

Zum schlusse wollen wiir noch einen blick auf übertragungen resp. bearbeitungen fremder gedichte werfen. Figentliche ïbersetzungen schrieb Aphra Belın nicht, sondern paraphrasen und nachahmungen. Von antiken dichtern hat sie Ovid und Horaz nachgeahımt. Eine paraphrase iiber eine ovidsche epistel haben wir schon oben genannt (p. 108). Dem gedichte ist zum verständnis für den leser folgendes ,argument“ vorausgeschickt: „Hecuba, beiing with Child of Paris, dream'd she was delivered of a Firebrand: Priam consulting the Prophets, was answer'd the :Child shou'd be the Destruction of Troy, wherefore Priam commanded it should be deliver'd to wild Beasts as soon as born ; but Hecuba conveys it secretly to Mount Ida, there to be fosster'd by the Shepherds, where

1) Poems 1684, p. 106. 
he falls in Love with the Nymph Oenone; but at last being known and own'd, he sails into Greece, and carries Helen to Troy, which Oenone understanding, writes him this Epistle." Oenone ruft Paris die geschichte ihrer zärtlichen liebe ins gedächtnis zurück; sie klagt in rührenden tönen über seine untreue und bittet ihn, sich nicht von der falschen Helena bestricken und in das ehejoch zwingen zu lassen, sondern wieder zu ihr zurückzukehren. Uebertriebene sentimentalität und das streben nach geistreichen gedanken kennzeichnen dieses gedicht.

Horaz ist in zwei kleineren gedichten vertreten. Das eine überschreibt die dichterin "In Imitation of Horace"; 1) es ist ein elegisch gehaltenes liebesgedicht. Das andere, „A Paraphrase on the eleventh Ode out of the first Book of Horace ",, besitzt den heiteren charakter wie die oben als horazischanakreontisch bezeichneten gedichte; sein inhalt lässt sich kurz durch die beiden verse wiedergeben:

Give me but Love and Wine, I'll ne'er

Complain my Destiny's severe.

Am ende der gedichtsammlung steht noch ein gedicht, das die verfasserin einfach "A Translation" ${ }^{3}$ ) nennt. Der inhalt stimmt genau mit dem eines gedichtes des Earl of Rochester iiberein, welches betitelt ist „A Lyric. In Imitation of Cornelius Gallus". ${ }^{4}$ ) Die beiden gedichte unterscheiden sich nur durch ihre länge, das erstere hat sieben, letzteres nur fünf, im übrigen gleichgebaute, strophen. Das original ist eine lateinische elegie aus dem fünfzehnten jahrhundert, die fälschlicherweise dem berühmten römischen redner und staatsmann zugeschrieben wurde; $\left.{ }^{5}\right)$ die elegie heisst „Lydia bella puella“.

In bezug auf die form, die sprache, den stil, entsprechen die gedichte Aphra Behns den anforderungen der galanten poesie. Die dichterin giebt selbst einmal eine bezeichnende charakteristik für gute verse in dem gedicht „On a Copy of Verses made in a Dream etc., $\left.{ }^{6}\right)$ wo sie die verse des Amyntas mit folgenden worten rühmt:

Soft ev'ry Word, easy each Line, and true;

Brisk, witty, manly, strong and gay;

1) Poems 1684, p. $98 . \quad$ 2) Poems 1684, p. $126 . \quad$ ") Poems 1624, p. 127.

4) The Poetical Works of the Earls of Rochester, Roscomon etc. p. 137.

s) Grässe, a. a. 0. p. $643 . \quad{ }^{6}$ ) Poems 1684, p. 63. 
The Thoughts are tender all, and new, And Fancy ev'ry where doess gently play.

Also sanfte worte, witzige verse, zarte, neue gedanken and lieblich spielende phantasie. Die sprache der gedichte Aphra Behns ist leicht verständlichı, nicht hochpoetisch, aber anmutig und beweglich. Umschreibiungen und vergleiche sind, im verhältnis z. b. zu dem schwulst in der gleichzeitigen deutschen dichtung, weniger häufig; wenn sie vorkommen, so sind es die allgemein üblichen undl konventionellen. So wird das reich der toten mit ewigen, schweigenden hainen, mit ewiger dämmerung verglichen; das therz der geliebten ist eine festung; die augen heissen lichtsterne; die wangen gleichen rosen, die von kristallschauern, dem thränen, betaut werden. Das streben nach neuen gedanken verleitet die dichterin zur geschraubtheit und zum wortschwall, die sich durch die häufung charakteristischer attribute kennzeichnnen; so nennt sie Celladon "the great, the brave and good, the plain and noble Character", oder Damon "the honest, brave and young“, oder die verse des Amyntas „brisk, witty, manly, strong, and gay“. Doch trotz der vielen worte ist der wortschatzz ziemlich beschränkt; es kehren immer dieselben ausdrücke wieder, die „sighing, lovely, true-hearted, witty, gay Swains" umd die „weeping, love-sick, pittyless, amorous, charming, blushimg Nymphs“, die „kindling Flames“, die „almighty, sacred, hopelless Love“, die „fine, starry, soft warring, killing Eyes", die "conquered, broken, yeilding Hearts“, die „coral Lips“, die „soft,, lucky, silent Hours", die gloomy, shady Groves", die "brolken Vows", etc. etc. Am besten, auch in bezug auf die form, sprache, sind der dichterin die heiteren gedichte wieder gelungen; sie zeichnen sich durch leichtigkeit und anmut aus. Wegen dieser vorzüge eignen sich diese gedichte, die Aphra Behn "Songs“ nennt, sehr wohl zur komposition, die einigen von ihnen zuteil geworden ist. ${ }^{1)}$ Leider ist gerade eines dieser lieder, "The willing Mistress", ebenso frivol und schlüpfrig im inhalt, wie anmutig und gewandt in der form; die letztere eigenschaft hat jedenfalls den deutschen dichter zur übersetzung gereizt. ${ }^{2}$ )

1) A Song on her loving Two equally: und The Counsel set by Capt. Pack. The Surprize set by Mr. Farmer. The Complaint set by Mr. Banister.

2) Siehe p. 128. 
Was die rein äussere form betrifft, so sind bei weitem über die hälfte der gedichte Aphra Behns in strophenform abgefasst. Die länge der strophen ist eine sehr verschiedene; sie schwankt zwischen vier und dreiundzwanzig versen. Die längeren strophen sind naturgemäss in den gedichten angewendet, in denen der ton feierlich, pathetisch sein soll. Dabei ist selbst innerhalb eines gedichtes die länge der einzelnen strophen nicht immer gleich; z. b. wechseln in der trauerode "On the Death of Mr. Grinhil" strophen von vierzehn, neunzehn, zweiundzwanzig und dreiundzwanzig versen mit einander. In den Songs sind die strophen immer gleich lang, da dies schon die melodie fordert. Die verse kommen auch in den verschiedensten längenmassen vor. Am zahlreichsten sind drei-, vierund fünfhebige verse mit einer senkung am anfang, also jambische verse. Längere, $d . h$. sechs- bis achthebige verse sind wieder in den feierlichen gedichten angewendet. In den Songs wechseln vielfach drei- und vierhebige verse regelmässig mit einander ab. Das metrum ist in den weitaus meisten fällen jambisch, selten trochäisch und nur in ganz wenig fällen daktylisch. Die verse sind ausnahmslos durch den reim gebunden. Die reimstellung bewegt sich in den mannigfachsten arten; wir begegnen paarweisen, gekreuzten und verschlungenen reimen. Auf die reinheit des reimklanges hat die dichterin keine besondere sorgfalt verwendet; oft sind die reime nur für das auge vorhanden, z. b. vow'd : show'd, move : love, all-cabal, turn : sun, vow : subdue, seen : him, set : great, etc.

Die unstrophischen gedichte sind aus versen zusammengesetzt, deren länge zwischen vier und sechs füssen schwankt. Es sind meist zwei, manchmal drei verse durch den reim gebunden. Die nachahmungen antiker gedichte weichen in der form nicht von den anderen gedichten $a b$; sie sind also auch entweder strophisch oder unstrophisch und stets gereimt.

Aphra Behn beherrscht diese einfachen formen sehr gut. Die verse sind glatt und leicht gebaut. Man merkt, dass ihr das versemachen leicht fiel. Ein beweis dafür liegt ja auch darin, dass sie die "Voyage to the Isle of Love“, deren original zum grösseren teil in prosa geschrieben ist, in leichte, fliessende verse gebracht hat.

Wir müssen hier noch auf zwei gedichte eingehen, die nicht mit sicherheit Aphra Behn zugeschrieben werden können. 
Es sind die beiden frivolisten in der sammlung: „On a Juniper'Tree" ${ }^{1)}$ und "The Disappointment". ${ }^{2}$ ) Diese beiden gedichte stehen merkwürdigerweiise auch in Rochesters gedichten. Es lässt sich nicht sicher ffeststellen, wer der autor der beiden gedichte ist; jedoch spretchen einige gründe für die autorschaft Aphra Behns, wenigstenss in bezug auf das zweite. Lowndes ${ }^{3}$ ) sagt von den gedichten des Earl of Rochester: „In this (ausgabe von 1680) and several other editions, are contained many poems full of obscenity, which are said to be falsely attributed to Lord Rochester." Alusserdem spricht noch ein umstand gegen Rochester. In sejinen Poems ist das gedicht, welches Aphra Behn "The Disappointment" nennt, betitelt: „The Insensible" $;^{4}$ ) dagegen stelht unmittelbar vorher ein anderes gedicht mit dem titel "The Disappointment", welches dieselben gedanken wie das Behnsche gedicht mit der gleichen überschrift behandelt, nur in anderer form. Daraus könnte man schliessen, dass Rochestter und Aphra Behn zu gleicher zeit denselben stoff behandeltten und dass vielleicht Rochester auch das gedicht Aphra Behnıs an sich nahm und in seine gedichtsammlung einfügte. Eimen direkten beweis, dass die beiden autoren zusammen gleiclhe stoffe bearbeiteten, besitzen wir in dem oben erwähnten gedichte Aphra Behns „A Translation“.5)

Wenn wir nach dem lobgedichten, die in den Poems 1684 vor den eigentlichen getdichten Aphra Behns stehen, urteilen wollten, so müssten wir annehmen, dass die dichterin mit ihren "Little Pieces" grossen anklang gefunden hat. Denn in diesen lobgedichten wird der diichterin von verschiedenen autoren, die aber nur zum teil ihren vollständigen namen nennen, die überschwänglichste huldigung gespendet. Alle stimmen darin überein, dass es nie vor:her eine so geniale dichterin gegeben labe wie Astrea und diass sie nie übertroffen werden würde. Diese panegyrischen ergiüsse kommen von befreundeten schriftstellern und sind natürlich nicht massgebend. Aphra Behn selbst urteilt ziemlich brescheiden über die kinder ihrer muse, wie wir oben gesehen haben. Allein die gedichte müssen doch

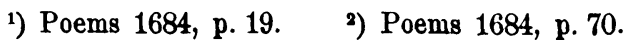

s) Lowndes, a. a. o. Part VIII, p. 2114.

4) The Poetical Works of the Earls of Rochester etc. p. 116.

s) Siehe p. 124. 
einen guten erfolg gehabt haben, denn Aphra Behn veranstaltete schon ein jahr darauf wieder eine ausgabe. ') Sie wurden sogar über England hinaus bekannt, vor allem in Deutschland. Hagedorn schreibt: „Der grosse Philip Sidney, der herzog von Buckingham, der graf Dorset, Sedley, der zärtliche Waller, die zärtlichere Aphra Behn, etc., sind die besten liederdichter der Engländer." 2) Ein anderer deutscher dichter jener zeit, Johann Burkard Mencke, bekannt unter seinem dichternamen Philander von der Linde, hat ein gedicht Aphra Behns übersetzt und zwar "The willing Mistress" ${ }^{\text {) }}$ („das willige Frauenzimmer"). In der vorrede $\mathrm{zu}$ seinen übersetzungen "verliebter" gedichte finden sich folgende anerkennende worte über Aphra Behn: „Die unter dem Nahmen der Astreea in Engeland allzu bekannte Afara Behn hätte weder anderen Personen ihrer Zeit so viel verliebte Gedanken inspiriret, noch die erdichtete Reise nach der Insul der Liebe in so anmutigen Reimen beschreiben können: wenn sie nicht nebst ihrer ungemeinen Schönheit auch eine ungemeine Empfindung gehabt." Die übersetzung des genannten gedichtes ist ziemlich frei und der sinn öfters nicht richtig wiedergegeben. Der ausdruck ist bei Aphra Behn knapper und gedrängter; in der übersetzung musste er schon deshalb weitschweifiger werder, weil der übersetzer alexandriner anwendete, während das original in abwechselnd drei- und vierhebigen versen gedichtet ist.

1) Siehe p. 106.

2) Hagedorns poet. werke; dritter teil; oden u. lieder; vorrede, p. IX.

s) Philanders von der Linde galante Gedichte, p. 51.

(Schluss folgt.)

LeIPZig.

P. Siegel. 